\title{
Bone Sarcomas: From Biology to Targeted Therapies
}

\author{
Nathalie Gaspar, ${ }^{1}$ Angela Di Giannatale, ${ }^{1}$ Birgit Geoerger, ${ }^{1}$ Françoise Redini, ${ }^{2}$ \\ Nadège Corradini, ${ }^{3}$ Natacha Enz-Werle, ${ }^{4}$ Franck Tirode, ${ }^{5}$ Perrine Marec-Berard, ${ }^{6}$ \\ Jean-Claude Gentet, ${ }^{7}$ Valérie Laurence, ${ }^{8}$ Sophie Piperno-Neumann, ${ }^{8}$ Odile Oberlin, ${ }^{1}$ \\ and Laurence Brugieres ${ }^{1}$
}

\author{
${ }^{1}$ Department of Oncology for Children and Adolescents, Institut Gustave Roussy, 114 rue Edouard Vaillant, \\ 94805 Villejuif Cedex, France \\ ${ }^{2}$ Inserm U957-EA 3822, Faculté de Médecine, 1 rue Gaston Veil, 44035 Nantes Cedex 1, France \\ ${ }^{3}$ Oncopediatric Departement, CHU de Nantes, Boulevard Jacques Monod, 44093 Nantes, France \\ ${ }^{4}$ Pediatric Onco-Hematology Department, EA 4438UdS, CHRU Strasbourg, Avenue Molière, 67000 Strasbourg, France \\ ${ }^{5}$ Unité 830 INSERM, Institut Curie, Centre de Recherche, 26 rue d'Ulm, 75248 Paris Cedex 05, France \\ ${ }^{6}$ Oncopediatric Departement, Centre Léon Bérard, 28 rue Laennec, 69008 Lyon, France \\ ${ }^{7}$ Oncopediatric Departement, Hôpital La Timone, 264 rue Saint Pierre, 13385 Marseille Cedex 5, France \\ ${ }^{8}$ Department of Medical Oncology, Institut Curie, 26 rue d'Ulm, 75248 Paris Cedex 05, France
}

Correspondence should be addressed to Nathalie Gaspar, nathalie.gaspar@igr.fr

Received 1 July 2012; Accepted 10 October 2012

Academic Editor: R. Pollock

Copyright (C) 2012 Nathalie Gaspar et al. This is an open access article distributed under the Creative Commons Attribution License, which permits unrestricted use, distribution, and reproduction in any medium, provided the original work is properly cited.

\begin{abstract}
Primary malignant bone tumours, osteosarcomas, and Ewing sarcomas are rare diseases which occur mainly in adolescents and young adults. With the current therapies, some patients remain very difficult to treat, such as tumour with poor histological response to preoperative CT (or large initial tumour volume for Ewing sarcomas not operated), patients with multiple metastases at or those who relapsed. In order to develop new therapies against these rare tumours, we need to unveil the key driving factors and molecular abnormalities behind the malignant characteristics and to broaden our understanding of the phenomena sustaining the metastatic phenotype and treatment resistance in these tumours. In this paper, starting with the biology of these tumours, we will discuss potential therapeutic targets aimed at increasing local tumour control, limiting metastatic spread, and finally improving patient survival.
\end{abstract}

\section{Introduction}

Primary bone sarcomas, osteosarcomas (OS), and Ewing sarcomas (EW) are diseases occurring mainly in adolescent and young adults and account for around $15 \%$ of childhood/adolescent cancers. First-line therapeutic strategies in these diseases consisted in chemotherapy (CT) before and after local treatment (including high-dose CT for highrisk EW [1]) and a local treatment by surgery but also or only by radiotherapy in EW. Some patients remain very difficult to treat, such as tumour with poor histological response to preoperative CT (or large initial tumour volume for EW not operated) [2,3], patients with multiple metastases at diagnostic $[1,4]$, or those who relapsed [5].
In order to develop new therapies against these diseases we need to unveil the founder molecular abnormalities underlying the malignant characteristics and to broaden our understanding of the phenomena sustaining the metastatic phenotype and treatment resistance in these tumours. Both diseases are sustained by different biology abnormalities but also share some common characteristics (angiogenesis, etc.).

The main objective of this paper is to discuss potential therapeutic targets aimed at increasing local control of the primary tumour, limiting metastatic spread, and finally improving patient survival. We then review preclinical data and both paediatric and adult trials performed or ongoing and choose to present them by pathway rather than by tumour. Table 1 and Figures 1 and 2 present the same data by tumour type. 


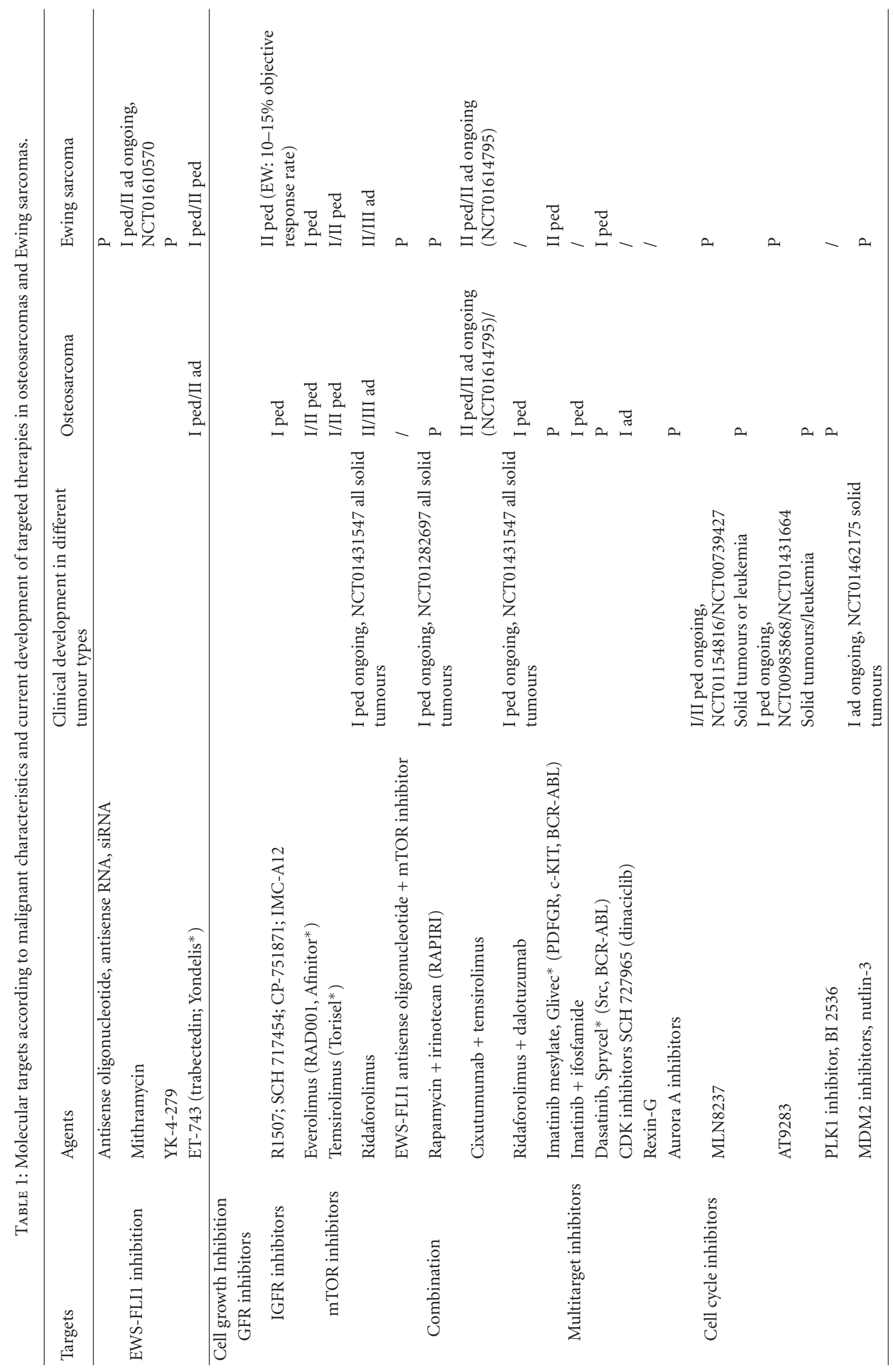




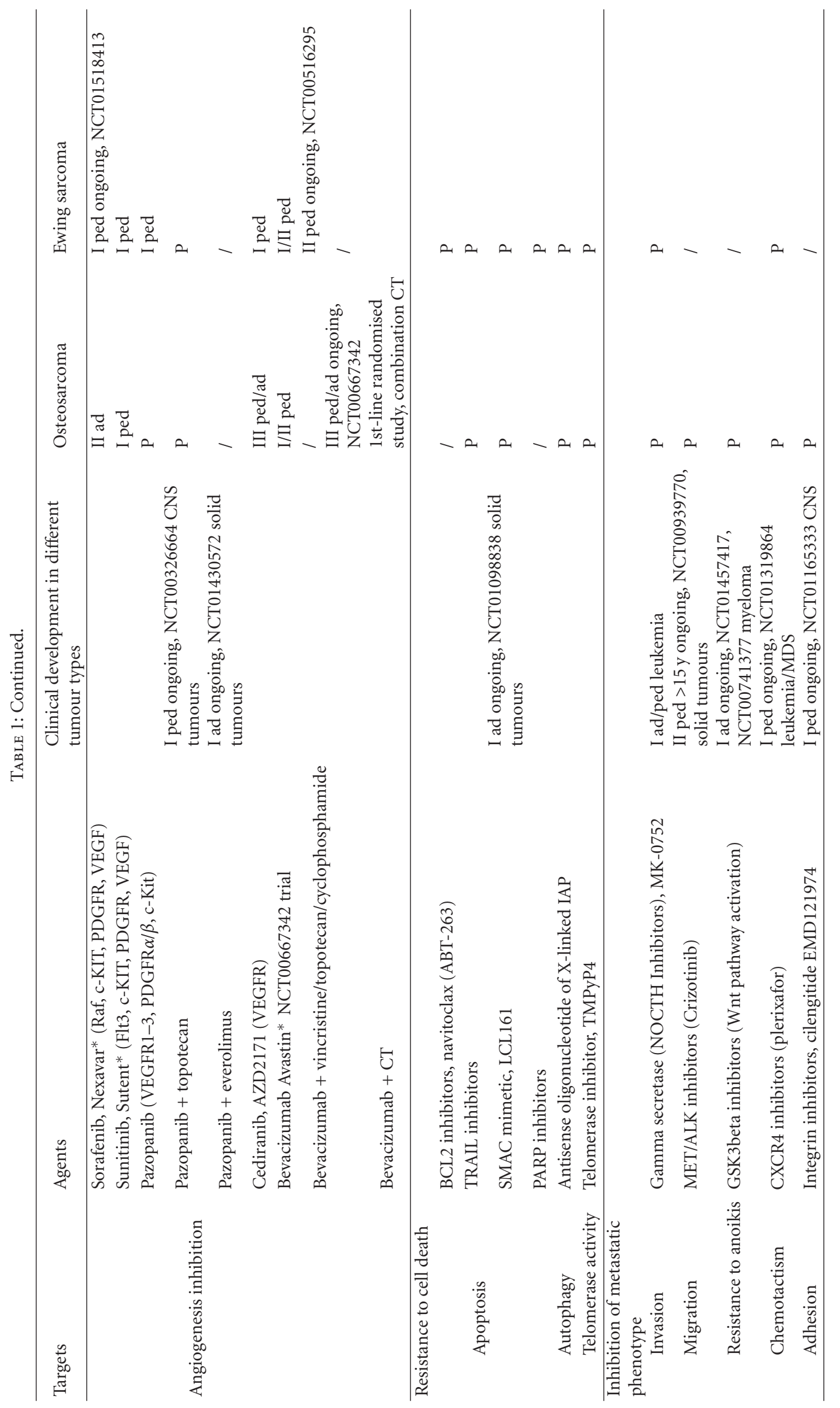




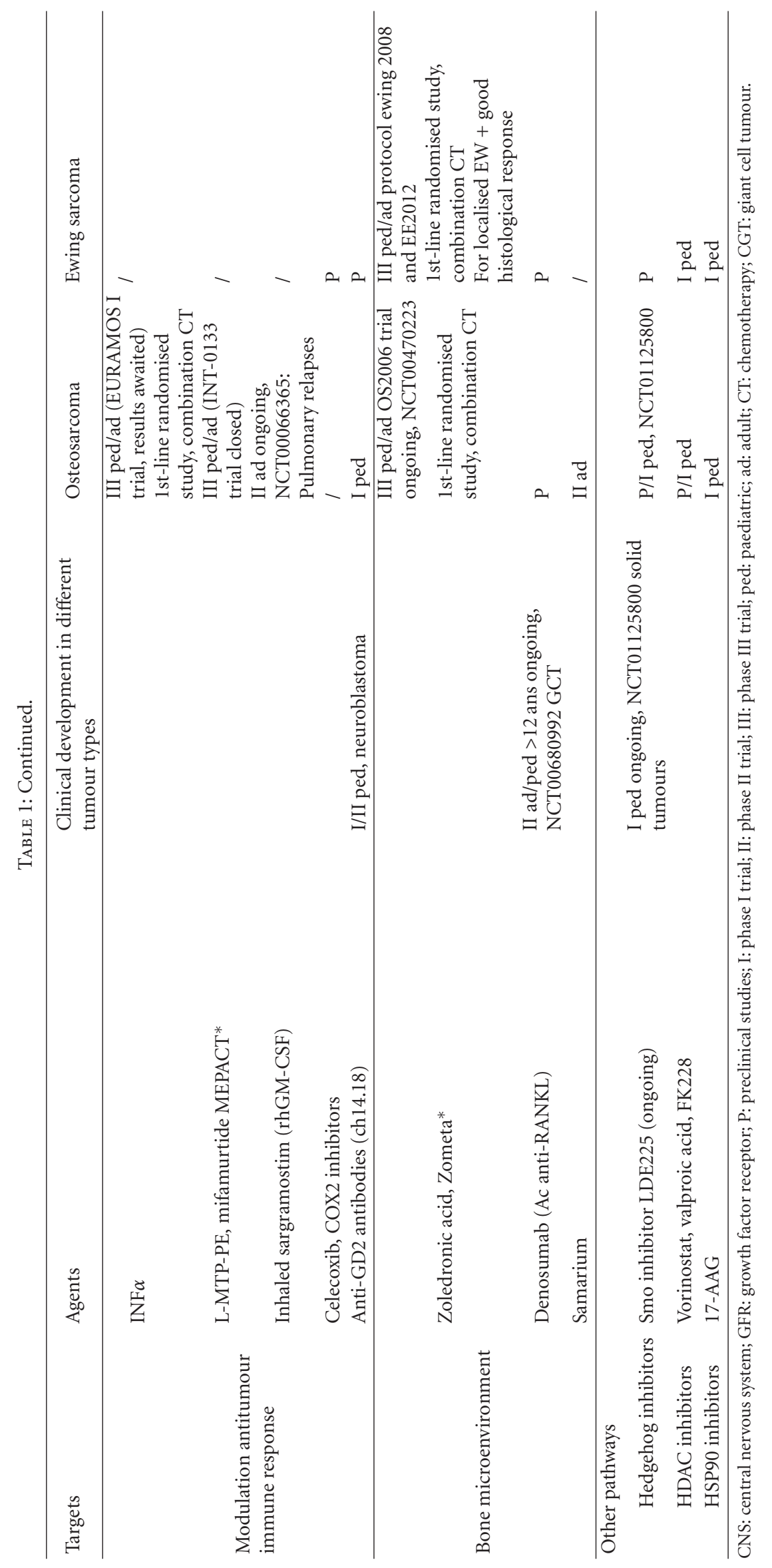




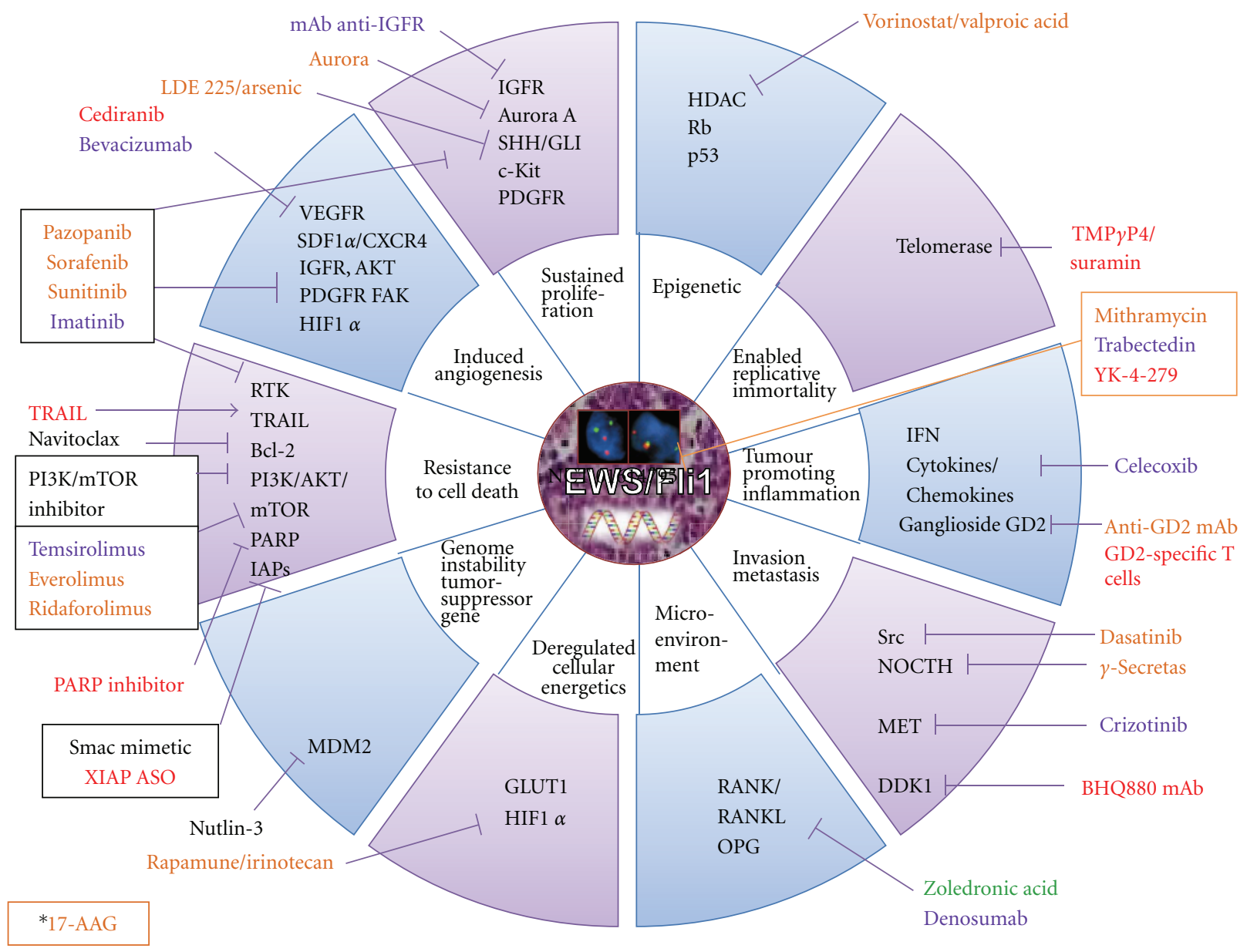

FIGURE 1: Targets and therapies in preclinical and clinical development in children and adolescent bone sarcomas. (A) Ewing sarcomas. (B) Osteosarcomas. The different colors described the current clinical development of the drugs. (Red) Preclinical: EW and OS; (Orange) Phase I: all paediatric studies; (Blue) Phase II: specific EW, OS, bone tumours; (Green) Phase III: specific EW and/or OS; (Black) Phase I or II in adults: all solid tumours. ${ }^{*} 17-\mathrm{AAG}$ is an HSP90 inhibitor which targets client proteins involved in all tumour characteristics.

\section{Biology of Bone Tumours}

\subsection{Biology of Ewing Sarcoma: A Cell of Mesenchymal Origin} Driven by an Aberrant Fusion Protein, EWS-Ets. EW is characterised by a group of translocations which oppose a gene from the EWS family with a gene from the ETS family arising in cells of mesenchymal origin [6]. The most frequent translocation is $\mathrm{t}(11 ; 22)$. It leads to an aberrant fusion protein which is responsible for the malignant phenotype [7]. EWS-Ets is a transcription factor with a DNA binding domain (Ets; FLI1 in 85\%) and a transcription enhancer domain (EWS) [8]. The altered intrinsic EWS-FLI1 region facilitates the formation of protein-protein interactions that regulate the transcription of numerous genes and mRNA alternative splicing [8]. Numerous biological pathways are modulated by EWS-FLI1 activity: IGFR, PDGFR, VEGFR, SHH pathway activation; Wnt, TGF $\beta$ RII pathway inhibition, and lead to the EW malignant phenotype: proliferation, angiogenesis, immune system escape, metastatic potential, and treatment resistance [8].
2.2. Biology of Osteosarcoma: Osteoblast or Cells of Mesenchymal Origin with a Complex Biology Producing Osteoid Matrix. OS is a malignant tumour that produces osteoid tissue. Different mesenchymal components found in different OS subtypes suggest that OS arise from a more pluripotent cell than the osteoblast.

OS belong to the spectrum of genetic predisposition to cancer syndromes (Li Fraumeni, hereditary retinoblastoma, Rothmund-Thomson, Werner syndromes). Molecular abnormalities influence various tumour characteristics and may be implicated in several biological pathways: sustaining proliferative signalling (IGFR, SHH/GLI, PDGFR, c-KIT), evading cell growth suppressors (p53, $\mathrm{RB}, \mathrm{CDK}$ ), resisting cell death (ERK activation, proapoptotic molecule inhibition, antiapoptotic molecule activation Bcl2, syndecan-2, autophagy inhibition), enabling replicative immortality (telomerase), increasing angiogenesis (VEGFR, IGFR, PDGFR, HIF1 $\alpha$ ), and activating invasion and metastasis, genome instability (p53, Rad51, GADD45), evading immune destruction (IFN), reprogramming energy 


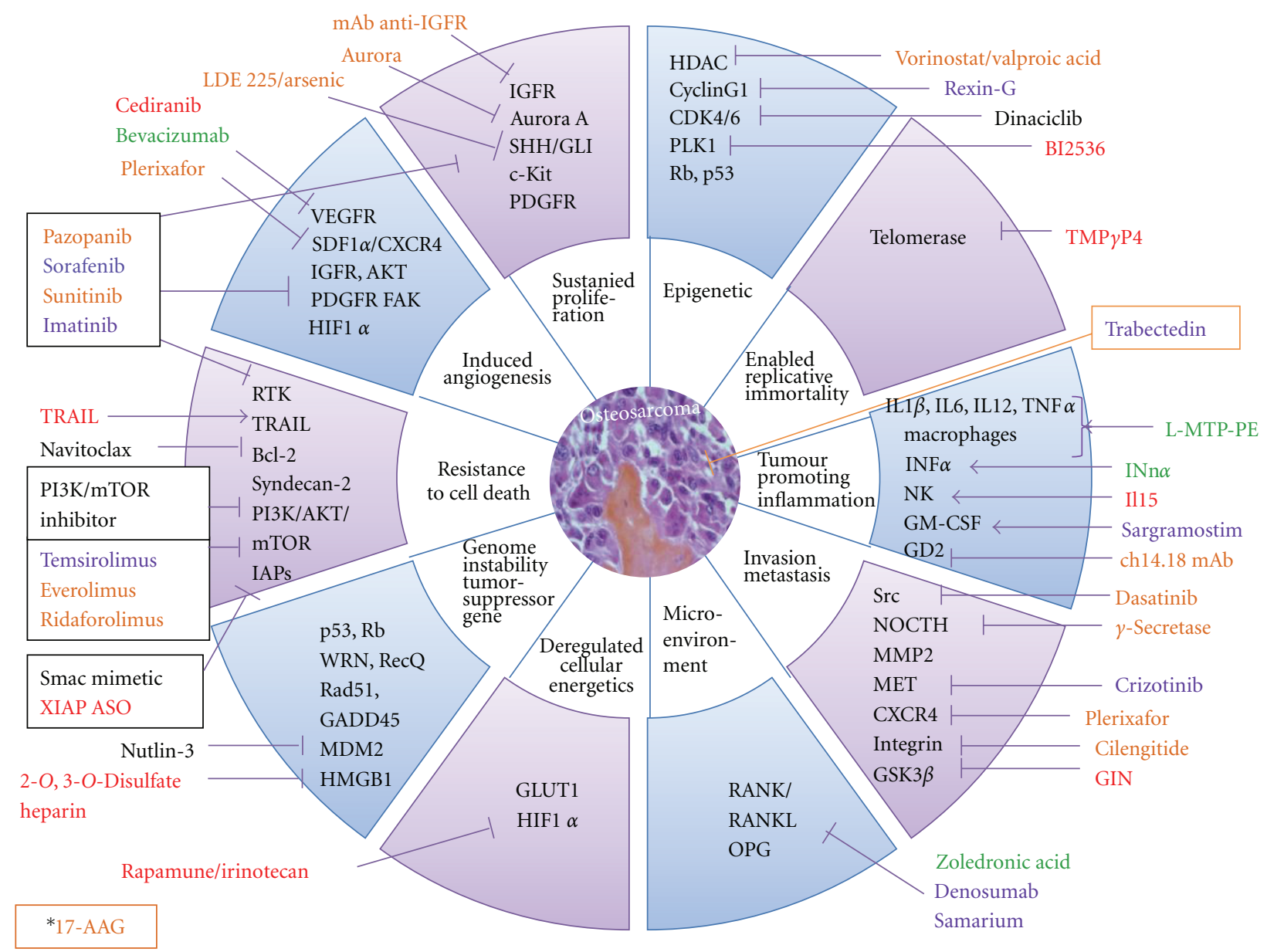

Figure 2

metabolism and hypoxic driven therapeutic resistance (HIF1 $\alpha$, GLUT1), and interacting with the bone microenvironment (RANK/RANKL/OPG).

\section{Therapeutic Options for Bone Sarcomas}

3.1. EWS-FLI1 Inhibition in Ewing Sarcomas. The fusion protein EWS-FLI1, exclusively expressed in EW tumour cells, is an ideal target for specifically treating EW without affecting normal cells.

Decreased EWS-FLI1 expression by antisense oligonucleotides [9] or RNA [10], small interference RNA (siRNA) through nanoparticles [11], inhibits cell proliferation and tumour growth of EW xenografts. The pharmacological delivery of these large molecules in patients is not yet solved. Mithramycin has been identified by high-throughput screening as another inhibitor of the EWS-FLI1 oncogenic transcription factor and has shown in vitro and in vivo activity against EW [12]. Mithramycin is currently being tested at the NCI against EW in children and adults (NCT01601570).

An alternative strategy is to target the interaction between EWS-FLI1 and its partner proteins in the transcriptional complexes in order to inhibit EWS-FLI1 function. YK-4-279 inhibits EWS-FLI1/RNA helicase A (RHA) interaction and induces apoptosis and tumour regression in EW models [13].

Trabectedin is an alkylating agent with increased efficacy in EW compared to other paediatric sarcomas (e.g., OS; rhabdomyosarcoma) through EWS-FLI1 inhibition [14, 15]. However, in children/adolescents, compassionate use of trabectedin and phases I/II trials yielded only one complete response (CR) lasting 6 months and stable diseases (SD) in 5 EW [14, 16-18]. In OS, only 2 partial responses (PR) out of 27 treated patients were observed. Tolerance in paediatric phases I/II trials $[14,16]$ was acceptable (thrombocytopenia, reversible hepatic toxicity).

Combined inhibition of EWS-FLI1 (oligonucleotide) and EWS-FLI1-modulated pathways (e.g., mTOR) increased the antitumour effect (apoptosis, in vivo tumour regression) [19].

3.2. Inhibition of Growth Factor Signalling Pathways. Most of the signalling pathways are involved in cell proliferation and resistance to apoptosis. They are mediated by proteins with kinase activity (tyrosine TK or serine SK kinases), located on the tumour cell surface, in the cytoplasm, or the nucleus. These proteins could be inhibited by two different approaches: monoclonal antibodies directed against 
extramembrane receptor and small molecule inhibitors of the intracellular kinase domain.

\subsubsection{The IGF-1R/PI3K/AKT/mTOR Pathway. The IGF-1R} pathway plays an important role in paediatric cancers, including OS/EW [20]. Both tumours have a peak incidence at puberty, and OS occur in an area of a high bone growth rate at long bone metaphyses, suggesting a role of growth hormone and IGF-1. Like others, the IGF-1R pathway activates downstream pathways $\mathrm{PI} 3 \mathrm{~K} / \mathrm{Akt} / \mathrm{mTOR}$ and stimulates OS/EW cell survival and angiogenesis through HIF- $1 \alpha$ and VEGF secretion.

With different anti-IGF-1R monoclonal antibodies, children/adolescents suffering from relapsed/refractory EW achieved SD in phase I trials [21] and an objective response rate of $10-15 \%$ in paediatric/adult phase II trials [22-24]. $\mathrm{SD}$ was observed in relapsed/refractory OS patients $(\mathrm{SCH}$ 717454, P04720, unpublished data, NCT00617890) [25].

Predictive factors of response remain insufficiently known. Reduced activity in an IGF system might be associated with tumour progression and poor response to treatment [26], high expression levels of IGF-IR, IR, and IGF-I mRNAs with increased survival, and high circulating IGF-1 levels with a low risk of progression [27].

Unfortunately, the median duration of EW response was only 5-7 months $[22,23]$, probably because tumour cells escape IGF-1R inhibition, through AKT or through activation of other signalling pathways (e.g., other TK receptors, mTOR) [28]. These observations have prompted clinical researchers to consider using either a combination of monotargeted inhibitors or multitargeted inhibitors.

Rapamycin, the mTOR inhibitor, was first used in children to prevent graft rejection. mTOR is an intracytoplasmic SK regulated by AKT. In OS cells, rapamycin inhibits proliferation through ezrin [29], a protein involved in intracellular signal transduction and migration [30]. In paediatric EW, phospho-mTOR overexpression is correlated with survival [31]. Paediatric phase I trials of everolimus [32] and temsirolimus [33] have demonstrated a good tolerance profile. One OS patient treated with everolimus achieved prolonged SD out of 5 patients treated with mTOR inhibitors [32]. The phase II trial of ridaforolimus in advanced bone and soft tissue sarcomas obtained a low response rate $<2 \%$ (2/4 responders had OS), but $28 \%$ obtained a clinical benefit [34]. A double blind phase III maintenance trial comparing ridaforolimus and placebo (SUCCEED trial) in advanced bone and soft tissue sarcoma after stabilisation or response with CT has included 50 bone sarcoma patients showing an increased progression free survival (PFS) in patients treated with ridaforolimus [35]. A paediatric phase II is ongoing in refractory/relapsed OS, in Brazil (NCT01216826). All these mTOR inhibitors inhibit TORC1. However, two mTOR complexes participate in two functionally disparate protein complexes, TORC1 and TORC2, both being associated with oncogenesis. TORC2 and subsequent AKT activation is suggested to induce resistance to TORC1 inhibition, and the dual TORC1/TORC2 small molecule inhibitor is being developed in adults (OSI-027, NCT00698243).
Strategies targeting the IGF-1R/PI3K/AKT/mTOR pathway simultaneously at several levels are being evaluated. An adult phase I combination of the anti-IGF1-R antibody cixutumumab and temsirolimus showed good tolerance and tumour regression of more than $20 \%$ in $5 / 17$ (29\%) EW patients who remained on study for 8 to 27 months, with a CR in 1/6 of EW patients who previously developed resistance to a different IGF-1R inhibitor antibody [36]. The phase II in younger patient with refractory (1-30 tears) or relapsed sarcomas is ongoing (NCT01614795) in USA. A phase I-II trial of ridaforolimus combined with the antiIGF1R antibody Dalotuzumab is ongoing (NCT01431547) in children in Europe and USA. Dual PI3K/mTOR inhibitors are being tested in an adult phase $\mathrm{I}$ trial and a dual mTOR/DNA-PK inhibitor (CC-115) in an adolescent/adult phase I trial (NCT01353625).

3.2.2. Multitarget Inhibitors. Imatinib mesylate inhibits PDGFR, c-KIT, and BCR-ABL. High expression of c-KIT and PDGFR is observed in EW/OS [37] and associated with low EFS but not with poor response to CT [37]. Imatinib appeared to exhibit anti-EW activity in vitro and in xenografts [38]. Expression of imatinib targets is not sufficient to confer drug sensitivity [39]. Several phase II trials have shown some stabilisation of bone sarcomas $(3 / 20$ EW, 7/26 OS) with a median PFS $<2$ months [40, 41]. In a COG paediatric phase II trial, only $1 / 24$ EW achieved a PR [42]. Preclinical data showed increased antitumour activity of imatinib when combined with doxorubicin and vincristine [43] in EW or ifosfamide in OS.

Dasatinib which inhibits Src and BCR-ABL shows in vitro cytostatic and antimigration effects and no apoptosis in EW [44]. Src plays a role in OS cell adhesion/migration through a decrease in FAK, but its inhibition does not prevent metastasis [45], suggesting that Src plays a secondary role in this process. A phase I paediatric trial showed similar dasatinib pharmacokinetics in children and adults [46].

Sorafenib inhibits BRaf, c-KIT, PDGFR, VEGFR, and RET. In OS, sorafenib inhibits proliferation of tumour growth, angiogenesis (VEGF), invasion (MMP2), and the emergence of pulmonary metastases (Erzin/ $\beta 4$-intégrin/ PI3K) and induces apoptosis [47]. A phase II trial of 35 patients $\geq 14$ years with OS under $2 \mathrm{nd} / 3$ rd-line therapy achieved $14 \%$ of objective responses (3PR, 2MR) and $29 \%$ of tumour control ( 12 additional SD). Tumour control lasted $\geq 6$ months for 8 patients. The median PFS and survival were 4 and 7 months, respectively [48].

Sunitinib inhibits Flt3, c-KIT, PDGFR, and VEGF. Efficacy was observed with in vivo models of most paediatric tumours, including 4/5 EW xenografts [49]. In a paediatric phase I trial, the main toxicities were haematological and cardiac for children previously treated with anthracyclines $[50,51]$.

Pazopanib inhibits VEGFR1-3, PDGFR $\alpha / \beta$, and c-KIT. Pazopanib showed activity in paediatric in vivo tumour models when used as a single agent (EW, EFS [52]) or combined with metronomic topotecan (OS, tumour regression [53]). A phase II study of pazopanib in relapsed bone sarcomas 
is ready to begin in Europe. The phase I in children with solid tumours showed good tolerance [54]. The combination pazopanib/everolimus is currently being tested in an adult phase I (NCT01430572). Furthermore, there is increasing information that mTOR inhibition can reverse resistance to growth receptor inhibition in other solid tumours including breast cancer [55, 56].

3.2.3. Cell Growth Inhibition Dependent on Cell Cycle Regulators. The CDK (cyclin-dependent kinase) inhibitor dinaciclib induces in vitro OS apoptosis [57]. The phase I/II trial of Rexin-G, a pathotrophic nanoparticle bearing a cytocidal cyclin G1 construct, in relapsed OS showed low toxicity, 2/3 SD, and survival lasting 7 months- [58]. Aurora A plays a crucial role during mitosis. The Aurora A inhibitor, MLN8237, led to prolonged CR in in vivo EW/OS models [59]. Two Aurora A inhibitors, MLN8237 (NCT01154816/NCT00739427) and AT9283 (NCT00985868/NCT01431664), are under development in paediatric phase I/II studies. The Polo-like kinase 1 (PLK1) selective inhibitor, BI 2536, exerted antiproliferative effects and induced mitotic death in OS cell lines [60].

MDM2 is an oncoprotein that negatively regulates p53 and is overexpressed in p53 wild-type cancers. The MDM2 inhibitor, nutlin-3, activates the p53 signalisation pathway leading to major tumour regressions in OS xenografts through apoptosis $[61,62]$. This effect is also seen in p53 wild-type EW and can be increased by either NF- $\kappa$ B inhibition [63] through TNF-alpha [64] or HDAC inhibitors [65]. An adult phase I of an oral MDM2 inhibitor (RO5503781) is ongoing in solid cancers (NCT01462175) and a study in sarcoma in preparation.

3.3. Resistance to Cell Death. Resistance to apoptosis is a key element in tumour progression and chemoresistance [66]. Its mechanisms are increased survival signals (growth factors/TK receptors, downstream pathways), overexpression of antiapoptotic molecules (Bcl-2, Bcl-XL, FAK in OS), underexpression of proapoptotic molecules (Bim in OS), or resistance to cell death receptors Fas/FasL (Fas ligand) or TRAIL. The BCL2 inhibitor, navitoclax, is developed in adult refractory tumours in combination with docetaxel. Toxicity is acceptable, and a few responses (2 PR, 5 SD) have been achieved [67]. TRAIL-induced apoptosis in murine models inhibits EW/OS tumour growth, decreases osteolysis, prolongs survival, and decreases lung metastases from OS [68]. Combining them with imatinib further increased TRAIL effect on tumour growth and metastases in in vivo EW models [69]. The fully human monoclonal antibody directed against DR5 (human death receptor 5), conatumumab, activates caspases, and induces apoptosis [70]. Phases I/II of conatumumab combined with the antiIGF1R antibody AMG479 in advanced sarcomas showed only SD (1OS/1EW) [71] and combined with doxorubicin did not show advantages compared to doxorubicin alone in advanced soft-tissue sarcomas [72]. IAPs (inhibitor of apoptosis proteins) inhibit caspase-dependent apoptosis. Smac, a mitochondrial protein, binds to IAPs, impedes the formation of the protective complex IAP/caspase, and facilitates caspase degradation by the proteasome. The Smac mimetic, LCL161, increases survival of paediatric in vivo models, including 5/6 OS and glioblastomas [73]. The adult phase I trial of LCL161 in solid tumours (NCT01098838) has just been completed, and a combination trial with paclitaxel is ongoing (NCT01240655). The X-linked IAP antisense oligonucleotide (XIAP ASO-AEG35156) in paediatric tumour cell lines decreases XIAP in OS, RMS, and EW and sensitizes OS to doxorubicin, etoposide, and vincristine [74]. Poly(ADPribose) polymerase (PARP) inhibitors induce apoptosis and tumour CR in EW models, and EWS-FLI1 fusion genes maintain the expression of PARP1, a DNA damage response protein and transcriptional coregulator, thereby enforcing oncogene-dependent sensitivity to PARP-1 inhibition [75]. Inhibition of survivin induces apoptosis [76] and reverts CT resistance (etoposide, cisplatin, and doxorubicin) in OS cell lines [77].

Autophagy, a cell survival process implicated in tumourigenesis and chemoresistance [78], participates, through HMGB1, in OS resistance to doxorubicin, cisplatin, and methotrexate. HMGB1 inhibition by siRNA restores chemosensitivity [79]. HMGB1 binds to Beclin1, which regulates the formation of the Beclin1-PI3KC3 complex and promotes autophagy. The 2-O,3-O-disulfate heparin (ODSH) is a low molecular weight anticoagulant with antiinflammatory activity but low anticoagulant activity [80]. It might exhibit an antitumour action through inhibition of heparinase (invasion), selectins (pulmonary metastatic spread), and RAGE II which is no longer able to bind to HMGB1 (proinflammatory and proautophagy roles).

Replicative immortality through the restoration of telomerase activity in cancer cells induces resistance to cell death. Telomerase activity is present in $85 \%$ of metastases ( $100 \%$ EW, $75 \%$ OS), but in only $12 \%$ of primary OS/EW tumours and associated with shortened telomeres and decreased patient survival [81]. The telomerase inhibitor, TMPyP4, inhibits telomerase enzyme activity, but inhibition of cell growth depends on the cellular context [82]. Telomerase activity is induced by EWS-FLI [83]. Telomerase is inhibited by suramin in OS [84] and imatinib [85], doxorubicin [86], or irradiation [87] in EW.

3.3.1. Inhibition of Angiogenesis and Hypoxia-Driven Resistance via mTOR Inhibition. Angiogenesis forms new capillaries from preexisting vessels, and vasculogenesis is the formation of new vessels from bone-marrow-derived progenitor cells [88]. PDGFR, VEGF, VEGFR and their downstream pathways (PI3K/AKT) are implicated in angiogenesis, VEGFR, and Notch (DLL4) in vasculogenesis, explaining the antiangiogenic effect of the multitargeted therapies described above. These receptors are overexpressed in OS/EW and associated with a poor prognosis [89, 90]. After cytotoxic CT, the number of bone marrow progenitor cells increases, promoting expansion of residual tumour cells or micrometastases [88]. Hypoxia increases these phenomena, especially through induction of HIF1 $\alpha$ expression [91], a factor associated with increased OS/EW aggressiveness 
$[92,93]$ and metastatic potential. HIF1 $\alpha$ expression is also induced by PI3K/AKT/mTOR, RAS/MAPK pathways, and calcium signalling. HIF $1 \alpha$ plays an additional role in bone sarcoma cell proliferation and apoptosis [94] and modulates EWS-FLI expression in EW [92].

Bevacizumab is an anti-VEGF IgG1 monoclonal antibody which inhibits VEGF/VEGFR-1 and VEGFR-2 interactions and VEGF-dependent angiogenesis. Tolerance in children/adolescents is good with a few side effects (proteinuria, thrombotic risk). A randomised phase II trial of bevacizumab combined with vincristine/topotecan/cyclophosphamide in first recurrent EW showed good tolerance (COG-AEWS0521, NCT00516295). A phase II trial combining bevacizumab with CT (MAP/MAPIE: methotrexate/adriamycin/platinum/ifosfamide/etoposide) as 1st-line therapy in OS is ongoing (NCT00667342).

Cediranib which inhibits VEGFR delayed tumour growth in $3 / 3 \mathrm{EW}$ and $4 / 5$ OS (1 CR) in in vivo models [95]. This delay in tumour growth was further increased when cediranib was combined with rapamycin, an mTOR inhibitor but not when combined with CT (vincristine, cyclophosphamide, cisplatin) [96]. DLL4 inhibitors are being tested in phase I in adults (neutralising antibody REGN421, NCT00871559). SDF-1 $\alpha$ /CXCR4 inhibition might also make it possible to target vasculogenesis, especially in tumours resistant to anti-VEGF therapies [88].

mTOR and topoisomerase I inhibitors decrease HIF- $1 \alpha$ accumulation leading to a major antitumour effect mainly when combined [97]. An SFCE (Société Française des Cancers de l'Enfant) paediatric phase I trial (RAPIRI, NCT01282697) combining rapamycin/irinotecan is ongoing.

3.4. Inhibition of the Metastatic Phenotype. Each step of the metastatic process could be targeted by different therapeutic classes [98]. OS invasion of the host extracellular matrix depends on the Notch/Hes1 pathway [99]. Its inhibition by gamma secretase inhibitors prevents the formation of metastases and induces tumour regression [9]. In EW, Notch is involved in neural differentiation, proliferation, and apoptosis, but its inhibition in established tumour models yielded a poor antitumour effect [100]. Paediatric phase I trials with the gamma secretase inhibitors MK-0752 in leukemia and CNS tumours showed good tolerance [101, 102].

Migration and the passage in the systemic circulation depend on the Met/HGF pathway [103, 104]. The ALK/MET inhibitor, crizotinib (PF-2341066), decreased proliferation, survival, invasion, and clonogenicity in vitro, tumour growth, and osteolysis in in vivo OS models [103, 105, 106]. A phase II for patients $\geq 15$ years is about to start in patients with MET or ALK-driven sarcoma and lymphomas (CREATE, NCT01524926).

Resistance to anoikis and the capacity to escape the immune system allow tumour cells to survive in the bloodstream. Anoikis is an apoptotic death induced by the loss of intercellular and cell/extracellular matrix contacts and depends on Src/PI3K/AKT and Wnt $/ \beta$-catenin/NF- $\kappa$ B pathways. In OS, GIN, the GSK3beta inhibitor stimulates the $\mathrm{Wnt} / \beta$-catenin pathway and induces intranuclear passage of $\beta$-catenin [107]. A phase I of the LY2090314 (GSK3 inhibitor)/pemetrexed/carboplatin combination is ongoing in adults with progressive solid tumours, with good tolerance and restoration of $\beta$-catenin expression [108]. DDK1 inhibitors interfere with the Wnt pathway and bone metabolism. Adult phase I studies with monoclonal antiDDK1 antibodies (LY2812176, NCT01457417; BHQ880, NCT00741377) are ongoing.

The arrival of circulating metastatic tumour cells in the lungs depends on chemokines and adhesion, then extravasation into target tissues depends on proteinases (MMP2, MMP9). CXCR4 is the main chemokine involved in OS [98]. CXCR4 inhibitors are used in humans to treat HIV infection and to mobilise hematopoietic stem cells (AMD3100, plerixafor). A paediatric phase I trial of plerixafor as chemosensitiser is ongoing in children with relapsed acute leukemia and myelodysplastic syndrome (NCT01319864). Adhesion and survival in the novel microenvironment depend on Erzin/ $\beta 4$ integrin/PI3K pathway and Fas/FasL-mediated resistance to apoptosis [109].

Dormancy is the prolonged survival in a quiescent state of isolated cells or micrometastases that might be responsible for late metastatic recurrences or resistance to cytotoxics. Dormancy depends on $\alpha \mathrm{v} \beta 1$ integrin activation of NF- $\kappa \mathrm{B}$, antiapoptotic molecule Bcl-XL, and the ERK/p38-MAPK ratio [110]. $\beta 4$ and $\beta 3$ integrins are expressed in OS and implicated in resistance to TNF $\alpha$-dependent apoptosis [111, 112]. Their inactivation is sufficient to revert the metastatic phenotype, but not inactivation of $\beta 1$ integrin. Cilengitide is the unique integrin inhibitor (high affinity selective antagonist of $\alpha \mathrm{v} \beta 3 / \alpha \mathrm{v} \beta 5$ ) currently under development in children. It induces the detachment of endothelial and tumour cells, disorganises the cytoskeleton and the tight junctions, induces apoptosis, and inhibits angiogenesis [98]. A paediatric phase I trial in brain tumours showed similar pharmacokinetics akin to that observed in adults and no dose limiting toxicity [113]. A paediatric phase I trial in combination with irradiation is ongoing for children/adolescents with diffuse brainstem high grade gliomas (CILENT-0902, trial NCT01165333).

3.5. Modulation of the Antitumour Immune Response. The immune system may play a major role in EW and OS cancer control. Interestingly, more rapid recovery of absolute lymphocyte count after the very first cycle of chemotherapy is associated with significantly improved survival for both EW and OS $[114,115]$.

In EW, the proinflammatory microenvironment (interferon, IFN) is more often seen in metastasis than in primary tumours and participates in neoangiogenesis (VEGFR secretion) and the metastatic potential (MMP9 secretion) $[116,117]$. The IFN/ifosfamide combination decreases these factors and inhibits tumour growth $[116,117]$ but at doses that cannot be reached in humans. The intratumour increase in proinflammatory type I cytokines/chemokines correlates with intratumour infiltration by cytotoxic T CD8+ lymphocytes which correlates with tumour progression 
[118]. In vivo, elevated C-reactive protein, a white blood cell count, and profuse vascularisation are associated with tumour macrophage infiltration which correlates with decreased survival [119]. In EW patients, fever is a prognostic factor whatever the metastatic status is [120]. Celecoxib, a COX2 inhibitor, exerts an antiproliferative effect in vitro and increases the cisplatin proapoptotic effect [121]. In vivo, it prevents pulmonary metastases without any effect on the primary tumour and its vascularisation [122].

The ganglioside, GD2, is expressed on the surface of EW/OS cells $[123,124]$. This neuroectodermic marker is targeted by an anti-GD2 monoclonal antibody, which, combined with IL2 and GM-CSF, has significantly increased the survival of metastatic neuroblastoma [125]. One OS patient treated in a phase I trial of ch14.18 had PD [126]. T cells were specifically modified to express the GD2-specific chimeric receptor 14. G2a-28zeta efficiently interacted with EW cells, resulting in antigen-specific secretion of cytokines. Moreover, chimeric receptor gene-modified $\mathrm{T}$ cells from healthy donors and from a patient exerted potent, GD2specific cytolytic responses to allogeneic and autologous EW, including tumour cells grown as multicellular, anchorageindependent spheres. GD2-specific T cells further had activity against EW xenografts [127]. Sargramostim (rhGM-CSF) induces myeloid dendritic cell differentiation facilitating the immune response mediated by $\mathrm{T}$ helper lymphocytes. However, the few objective responses were transient [128]. Inhaled sargramostim showed no detectable immunostimulatory effect in pulmonary metastases or improved outcome postrelapse (phase II NCT00066365) [129]. Recently, the identification of the first EFT-specific immunogenic T-cell epitope might lead to a better understanding of EFT immunology and may improve dendritic cell-based immunotherapy [130].

In OS, INF $\alpha / \beta$ expression correlates with a better outcome [131], and the presence of infiltrative macrophages is associated with a decreased incidence of metastasis and prolonged survival [132]. IFN $\alpha$ induces HLA class I molecule expression and exerts an antiproliferative effect [133]. The results of the randomised combination of IFN $\alpha$ with first-line CT in OS (EURAMOS I) are pending. IFN $\gamma$ increases tumour cell surface expression of FAS and lymphocyte $\mathrm{T} \gamma \delta$ cytotoxicity [134]. L-MTP-PE (muramyl tripeptide phosphatidyl ethanolamine liposomal) stimulates the antitumour effect of monocytes/macrophages, facilitates the secretion of proinflammatory cytokines with direct cytotoxic anti-tumour effects (IL1 $\beta$, IL6, TNF $\alpha$ ) [135], and induces IL12 which destroys circulating OS cells [109]. The US randomised phase III study of L-MTP-PE combined with 1st-line MAP/MAPIE CT in OS (INT-00133) appeared to be in favour of the combination, with a possible positive interaction between L-MTP-PE/ifosfamide [135]. However, the US Food and Drug Administration (FDA) did not approve MTP-PE use in OS, while the European Medicines Agency (EMA) allowed it. OS cells, including chemoresistant variants (doxorubicin, methotrexate, cisplatin), are highly susceptible to lysis by IL-15induced NK cells of both allogeneic and autologous origin [132].
3.6. Modulation of the Bone Microenvironment. Bone tumours are characterized by a vicious cycle between tumour growth and osteolysis, marked by the activity of RANK and its ligand (RANKL), key mediators of osteoclast differentiation, function, and survival [136]. RANKL facilitates osteoclastogenesis, bone resorption, growth factor secretion which participates in bone destruction, tumour growth, and intraosseous migration of RANK+ cells [137]. For OS patients, RANKL tumour expression is associated with a poor response to preoperative CT, high expression with decreased survival, and high TRACP5b plasma levels (osteoclastic activity marker) with the occurrence of metastases [138, 139].

Zoledronic acid, a potent inhibitor of bone resorption by inducing osteoclast apoptosis, also inhibits RANK expression and osteoclast progenitor migration during osteoclastogenesis and increases osteoprotegerin (OPG) expression [140]. In preclinical OS models, it exerts direct antiproliferative [141], proapoptotic/anoikis [142-144], and antiangiogenic effects [145], decreases bone resorption, and exhibits antitumour activity [140, 146-148]. Contradictory data on metastases suggest preventive [143,148, 149], inexistent [147], or prometastatic effects [150]. It overcomes OS resistance to cisplatin [151], irradiation [152], and mTOR inhibitors [145], in vitro, and to paclitaxel [140] and ifosfamide [146], in vivo. Zoledronic acid combined with 1st-line methotrexate or adriamycin/platinum/ifosfamide-based CT in OS is currently being tested in the French randomised phase III trial (OS2006, NCT00470223). In in vivo EW models, zoledronic acid alone is only active against the bone tumour. An effect on extraosseous tumour components is obtained when zoledronic acid is combined with ifosfamide [153]. The use of zoledronic acid in combination with 1stline chemotherapy is being addressed for localised EW in Europe, in randomised phase III trials (the current Ewing 2008 and future Euro-EWING2012). In juvenile models, zoledronic acid decreases enchondral bone growth in a reversible manner [154].

In preclinical OS models, inhibition of RANKL signalling by a decoy receptor OPG or with a soluble form of its membranous receptor RANK (RANK-Fc) inhibits tumourassociated osteolysis and reduces tumour incidence, local growth, invasion, migration, and lung metastases, leading to increased survival in animals [155-157]. However, RANKL inhibition has no effect in OS cells in vitro [155-157]. An additive effect of RANKL inhibition with CT was observed in OS models [158]. Fewer data are available in EW, but indirect RANKL inhibition leads to inhibition of osteoclastic activity $[159,160]$.

Denosumab is a humanised monoclonal antibody (IgG2) with high affinity and specificity against RANKL and is interesting in several cancers with bone metastases [161]. A phase II safety study of denosumab in subjects $\geq 12$ years with a recurrent/unresectable bone giant cell tumour is ongoing (NCT00680992) [162].

In addition to the antiangiogenic effects, DDK1 inhibition (Wnt pathway) by the monoclonal antibody BHQ880 might restore bone formation but without a direct antitumour effect. BHQ880 is currently being investigated in 
adult phase I/II trials for multiple myeloma, alone (NCT01302886;NCT01337752) or associated with zoledronic acid (NCT00741377).

Bone-seeking radiopharmaceuticals provide another bone-specific means to target OS cells, which make bone. The standard $99 \mathrm{mTc}-\mathrm{MDP}$ bone scan is the screening test of this characteristic needed for targeting. The beta emitting 153Sm-EDTMP (Samarium) is FDA approved for osteoblastic bone metastases and is useful for palliation of pain. A newer alpha-emitting radiopharmaceutical, 223Ra (Alpharadin), may be not only more safe (less marrow toxicity) but also more effective because the dense energy deposited by alpha particles produce double strand breaks [163-166].

\subsection{Other Exploitable Therapeutic Pathways}

3.7.1. Hedgehog Pathway Inhibitors (SHH/PATCH/Smo/GLI). The Hedgehog signalling pathway plays an key role in growing organisms (embryogenesis, morphogenesis) and is activated in OS/EW (GLI is an EWS-FLI1 target) [167, 168]. Its inhibition by cyclopamine in OS [169] and arsenic trioxide, a GLI inhibitor, in EW [168], stunts tumour growth. Arsenic trioxide reverts multi-CT resistance in OS cell lines [170]. A paediatric phase I study is ongoing testing LDE225, a smoothened inhibitor (NCT01125800). Its effects on bone growth might be of concern. Another inhibitor of this pathway is Itraconazole at an antifungal dose [171].

3.7.2. Histone Deacetylase (HDAC) Inhibitors. HDAC and histone acetyltransferase (HAT) are enzymes which catalyse histone deacetylation and acetylation, respectively, and modify chromatin access to transcription factors and gene transcription. Two paediatric phase I trials have been completed with two HDAC inhibitors (vorinostat and valproic acid) $[172,173]$.

In OS models, HDAC inhibitors decrease DNA repair capacity [174], sensitising cells to irradiation [175] and doxorubicin $[176,177]$, facilitate Fas-dependent cell death by increasing Fas expression on tumour cells which die through apoptosis in the presence of FasL (lung) [178], and decrease FLIP expression, a negative regulator of caspase 8 [179]. SNDX-275 nasal administration exerts a preventive action against pulmonary metastases in murine OS models [178]. Valproic acid increases membrane HLA class I molecule expression, sensitizing OS cells to NK cytotoxicity [180]. HDAC inhibitors are suspected of negative effects in OS, through the induced expression of Notch genes and invasion, which might facilitate the OS metastatic potential [99].

In EW cells, EWS-FLI1 represses HAT and activates HDAC [181]. HDAC inhibition restores HAT activity, inhibits cell growth, and induces apoptosis [182]. FK228 decreases EWS-FLI1 expression and EW proliferation [181] and induces TRAIL-dependent apoptosis [183].

Acquired resistance to the cyclic tetrapeptide family HDAC inhibitor (FK228) is mediated by $\mathrm{P}$ glycoprotein (PgP), a drug efflux pump and the MAPK pathway, and might be reverted with verapamil (EW) [184] and MEK inhibitors (OS) [185].

3.7.3. Heat Shock Protein 90 (HSP90) Inhibitors. HSP90 is a chaperone protein implicated in numerous cancers. It is overexpressed in 21/54 EW patient samples [186]. AntiHSP90 antibodies in sera are associated with a poor response to CT in OS [84].

HSP90 inhibitors induce proteasome-mediated degradation of many oncogenic proteins involved in all hallmark characteristics of cancer. 17-AAG induces in vitro apoptosis [29] and in vivo tumour growth retardation in OS as a single agent and in combination with cisplatin [187] and restores the efficacy of the IGF1R inhibitor and imatinib in EW models [186]. No objective response was observed in two paediatric phase I trials (SD $1 / 3 \mathrm{EW}, 0 / 7 \mathrm{OS}$ ). However, acquired resistance to $17-\mathrm{AAG}$ is rapid [188], and new generations of HSP90 inhibitors might be more promising (adult phase I/II trials ongoing).

\section{Conclusion}

The multiplicity of targets in primary malignant bone tumours in children/adolescents, the increasing number of new molecular therapies becoming available, and the rarity of these tumours will not allow testing all of the strategies which are discussed in this paper. Consequently, prioritisation in drug development as well as new methodologies for the development of therapeutic trials will be required.

In EW, the development of therapies targeting the EWSFLI founder genetic abnormalities is crucial, but currently at an extremely early stage. The experience with anti-IGF1R antibodies suggests that the inhibition of EWS-FLI targets might be useful to control the disease in some patients but not in a prolonged manner if used as monotherapy. Combination with CT should be tested, and a better understanding of the predictive factors of response is compulsory. In addition, due to the multiplicity of EWS-FLI targets and the pathways redundancies, simultaneous inhibition of growth factor receptor and downstream pathways might be useful to overcome some resistance, as well as, targeting different characteristics of the tumour and the environment such as bone microenvironment (Zometa phase III), angiogenesis (bevacizumab phase II), and antitumoural immunity (antiGD2 humoral or cellular immunity).

In OS, no founder mutation is known and more efforts are necessary to understand the biological processes implicated in OS oncogenesis. Strategies targeting antitumoural immunity (MTP-PE, phase III first-line trial), angiogenesis (sorafenib, phase II trial), and bone microenvironment (zoledronic acid, preclinical data) appear promising, including in association with cytotoxic CT. Combining these strategies together and with first-line CT as well as developing therapies directed against the metastatic process (e.g., MET inhibitors) might further improve OS outcome. In conclusion, future therapeutic strategies against bone tumours will reside in the way we combine therapies targeting different characteristics of the malignant cells and their environment. 


\section{Abbreviations}

$\begin{array}{ll}\text { CR: } & \text { Complete response } \\ \text { CT: } & \text { Chemotherapy } \\ \text { EFS: } & \text { Event-free survival } \\ \text { EMA: } & \text { European Medicines Agency } \\ \text { EW: } & \text { Ewing sarcoma } \\ \text { FDA: } & \text { The US Food and Drug Administration } \\ \text { HAT: } & \text { Histone acetyltransferase } \\ \text { HDAC: } & \text { Histone deacetylase } \\ \text { IAP: } & \text { Inhibitor of apoptosis proteins } \\ \text { IGF-1R: } & \text { Insulin-like-growth-factor 1 receptor } \\ \text { OPG: } & \text { Osteoprotegerin } \\ \text { OS: } & \text { Osteosarcoma } \\ \text { PD: } & \text { Progressive disease } \\ \text { PFS: } & \text { Progression free survival } \\ \text { PPTP: } & \text { Pediatric Preclinical Testing Program } \\ \text { PR: } & \text { Partial response } \\ \text { RANK: } & \text { Receptor activator of nuclear factor- } \kappa \mathrm{B} \\ \text { RANKL: } & \text { RANK ligand } \\ \text { SD: } & \text { Stable disease } \\ \text { SFCE: } & \text { Société Française des Cancers de l'Enfant } \\ \text { siRNA: } & \text { Small interference RNA. }\end{array}$

\section{Acknowledgments}

The authors thank Lorna Saint-Ange for the editing and Karim Fizazi, Clarisse Baumann, Christophe Glorion and Michel Ducreux for the review of this paper.

\section{References}

[1] R. Ladenstein, U. Pötschger, M. C. Le Deley et al., "Primary disseminated multifocal Ewing sarcoma: results of the EuroEWING 99 trial," Journal of Clinical Oncology, vol. 28, no. 20, pp. 3284-3291, 2010.

[2] O. Oberlin, M. C. L. Deley, B. N. G. Bui et al., "Prognostic factors in localized Ewing's tumours and peripheral neuroectodermal tumours: the third study of the french society of paediatric oncology (EW88 study)," British Journal of Cancer, vol. 85, no. 11, pp. 1646-1654, 2001.

[3] M. C. Le Deley, J. M. Guinebretière, J. C. Gentet et al., "SFOP OS94: a randomised trial comparing preoperative high-dose methotrexate plus doxorubicin to high-dose methotrexate plus etoposide and ifosfamide in osteosarcoma patients," European Journal of Cancer, vol. 43, no. 4, pp. 752-761, 2007.

[4] E. E. Pakos, A. D. Nearchou, R. J. Grimer et al., "Prognostic factors and outcomes for osteosarcoma: an international collaboration," European Journal of Cancer, vol. 45, no. 13, pp. 2367-2375, 2009.

[5] M. Stahl, A. Ranft, M. Paulussen et al., "Risk of recurrence and survival after relapse in patients with Ewing sarcoma," Pediatric Blood and Cancer, vol. 57, no. 4, pp. 549-553, 2011.

[6] F. Tirode, K. Laud-Duval, A. Prieur, B. Delorme, P. Charbord, and O. Delattre, "Mesenchymal stem cell features of Ewing tumors," Cancer Cell, vol. 11, no. 5, pp. 421-429, 2007.

[7] S. Benini, M. C. Manara, V. Cerisano et al., "Contribution of MEK/MAPK and PI3-K signaling pathway to the malignant behavior of Ewing's sarcoma cells: therapeutic prospects," International Journal of Cancer, vol. 108, no. 3, pp. 358-366, 2004.
[8] H. V. Erkizan, V. N. Uversky, and J. A. Toretsky, "Oncogenic partnerships: EWS-FLI1 protein interactions initiate key pathways of Ewing's sarcoma," Clinical Cancer Research, vol. 16, no. 16, pp. 4077-4083, 2010.

[9] K. Tanaka, T. Iwakuma, K. Harimaya, H. Sato, and Y. Iwamoto, "EWS-Fli1 antisense oligodeoxynucleotide inhibits proliferation of human Ewing's sarcoma and primitive neuroectodermal tumor cells," Journal of Clinical Investigation, vol. 99, no. 2, pp. 239-247, 1997.

[10] A. Maksimenko, G. Lambert, J. R. Bertrand, E. Fattal, P. Couvreur, and C. Malvy, "Therapeutic potentialities of EWSFli-1 mRNA-targeted vectorized antisense oligonucleotides," Annals of the New York Academy of Sciences, vol. 1002, pp. 7277, 2003.

[11] S. Hu-Lieskovan, J. D. Heidel, D. W. Bartlett, M. E. Davis, and T. J. Triche, "Sequence-specific knockdown of EWS-FLI1 by targeted, nonviral delivery of small interfering RNA inhibits tumor growth in a murine model of metastatic Ewing's sarcoma," Cancer Research, vol. 65, no. 19, pp. 8984-8992, 2005.

[12] P. J. Grohar, G. M. Woldemichael, L. B. Griffin et al., "Identification of an inhibitor of the EWS-FLI1 oncogenic transcription factor by high-throughput screening," Journal of the National Cancer Institute, vol. 103, no. 12, pp. 962-978, 2011.

[13] H. V. Erkizan, Y. Kong, M. Merchant et al., "A small molecule blocking oncogenic protein EWS-FLI1 interaction with RNA helicase A inhibits growth of Ewing's sarcoma," Nature Medicine, vol. 15, no. 7, pp. 750-756, 2009.

[14] S. Baruchel, A. Pappo, M. Krailo et al., "A phase 2 trial of trabectedin in children with recurrent rhabdomyosarcoma, Ewing sarcoma and non-rhabdomyosarcoma soft tissue sarcomas: a report from the Children's Oncology Group," European Journal of Cancer, vol. 48, no. 4, pp. 579-585, 2012.

[15] P. J. Grohar, L. B. Griffin, C. Yeung et al., "Ecteinascidin 743 interferes with the activity of EWS-FLI1 in ewing sarcoma cells," Neoplasia, vol. 13, no. 2, pp. 145-153, 2011.

[16] L. Lau, J. G. Supko, S. Blaney et al., "A phase I and pharmacokinetic study of ecteinascidin-743 (Yondelis) in children with refractory solid tumors. A Children's Oncology Group study," Clinical Cancer Research, vol. 11, no. 2 I, pp. 672-677, 2005.

[17] S. Delaloge, A. Yovine, A. Taamma et al., "Ecteinascidin-743: a marine-derived compound in advanced, pretreated sarcoma patients-preliminary evidence of activity," Journal of Clinical Oncology, vol. 19, no. 5, pp. 1248-1255, 2001.

[18] A. Le Cesne, A. Yovine, J. Y. Blay et al., "A retrospective pooled analysis of trabectedin safety in 1,132 patients with solid tumors treated in phase II clinical trials," Investigational New Drugs, vol. 30, pp. 1193-1202, 2012.

[19] S. Mateo-Lozano, P. C. Gokhale, V. A. Soldatenkov, A. Dritschilo, O. M. Tirado, and V. Notario, "Combined transcriptional and translational targeting of EWS/FLI-1 in Ewing's sarcoma," Clinical Cancer Research, vol. 12, no. 22, pp. 6781-6790, 2006.

[20] W. D. Tap, "AMG 479 in relapsed or refractory Ewing's family tumors (EFT) or desmoplastic small round cell tumors (DSRCT): phase II results," Journal of Clinical Oncology, vol. 28, supplement, abstract 10001, p. 15s, 2010.

[21] D. Olmos, S. Postel-Vinay, L. R. Molife et al., "Safety, pharmacokinetics, and preliminary activity of the anti-IGF$1 \mathrm{R}$ antibody figitumumab (CP-751,871) in patients with sarcoma and Ewing's sarcoma: a phase 1 expansion cohort study," The Lancet Oncology, vol. 11, no. 2, pp. 129-135, 2010. 
[22] A. S. Pappo, S. R. Patel, J. Crowley et al., "R1507, a monoclonal antibody to the insulin-like growth factor 1 receptor, in patients with recurrent or refractory Ewing sarcoma family of tumors: results of a phase II Sarcoma Alliance for Research through Collaboration study," Journal of Clinical Oncology, vol. 29, no. 34, pp. 4541-4547, 2010.

[23] H. Juergens, N. C. Daw, B. Geoerger et al., "Preliminary efficacy of the anti-insulin-like growth factor type 1 receptor antibody figitumumab in patients with refractory Ewing sarcoma," Journal of Clinical Oncology, vol. 29, no. 34, pp. 4534-4540, 2011.

[24] S. Malempati, B. Weigel, A. M. Ingle et al., "Phase I/II trial and pharmacokinetic study of cixutumumab in pediatric patients with refractory solid tumors and Ewing sarcoma: a report from the Children's Oncology Group," Journal of Clinical Oncology, vol. 30, no. 3, pp. 256-262, 2012.

[25] P. Anderson, K. Skubitz, R. Miller et al., "Activity of SCH 717454 in subjects with relapsed osteosarcoma or Ewing's sarcoma (study P04720)," in Proceedings of the 14th Annual Meeting of the Connective Tissue Oncology Society, Abstract \#35094, London, UK, 2007.

[26] A. L. Ho and G. K. Schwartz, "Targeting of insulin-like growth factor type 1 receptor in Ewing sarcoma: unfulfilled promise or a promising beginning?" Journal of Clinical Oncology, vol. 29, no. 34, pp. 4581-4583, 2011.

[27] K. Scotlandi, M. C. Manara, M. Serra et al., "Expression of insulin-like growth factor system components in Ewing's sarcoma and their association with survival," European Journal of Cancer, vol. 47, no. 8, pp. 1258-1266, 2011.

[28] C. Garofalo, M. C. Manara, G. Nicoletti et al., "Efficacy of and resistance to anti-IGF-1R therapies in Ewing's sarcoma is dependent on insulin receptor signaling," Oncogene, vol. 30, no. 24, pp. 2730-2740, 2011.

[29] Y. Gazitt, V. Kolaparthi, K. Moncada, C. Thomas, and J. Freeman, "Targeted therapy of human osteosarcoma with 17AAG or rapamycin: characterization of induced apoptosis and inhibition of mTOR and Akt/MAPK/Wnt pathways," International Journal of Oncology, vol. 34, no. 2, pp. 551-561, 2009.

[30] X. Wan, A. Mendoza, C. Khanna, and L. J. Helman, "Rapamycin inhibits ezrin-mediated metastatic behavior in a murine model of osteosarcoma," Cancer Research, vol. 65, no. 6, pp. 2406-2411, 2005.

[31] J. Mora, E. Rodríguez, C. de Torres et al., "Activated growth signaling pathway expression in Ewing sarcoma and clinical outcome," Pediatric Blood \& Cancer, vol. 58, no. 4, pp. 532$538,2012$.

[32] M. Fouladi, F. Laningham, J. Wu et al., "Phase I study of everolimus in pediatric patients with refractory solid tumors," Journal of Clinical Oncology, vol. 25, no. 30, pp. 4806-4812, 2007.

[33] S. L. Spunt, S. A. Grupp, T. A. Vik et al., "Phase I study of temsirolimus in pediatric patients with recurrent/refractory solid tumors," Journal of Clinical Oncology, vol. 29, no. 21, pp. 2933-2940, 2011.

[34] S. P. Chawla, A. P. Staddon, L. H. Baker et al., "Phase II study of the mammalian target of rapamycin inhibitor ridaforolimus in patients with advanced bone and soft tissue sarcomas," Journal of Clinical Oncology, vol. 30, no. 1, pp. 7884, 2012.

[35] S. P. Chawla, "Results of the phase III, placebo-controlled trial (SUCCEED) evaluating the mTOR inhibitor ridaforolimus (R) as maintenance therapy in advanced sarcoma patients (pts) following clinical benefit from prior standard cytotoxic chemotherapy (CT)," Journal of Clinical Oncology, vol. 29, supplement, abstract 10005, 2011.

[36] A. Naing, P. LoRusso, S. Fu et al., "Insulin Growth FactorReceptor (IGF-1R) antibody cixutumumab combined with the mTOR inhibitor temsirolimus in patients with refractory Ewing's sarcoma family tumors," Clinical Cancer Research, vol. 18, no. 9, pp. 2625-2631, 2012.

[37] T. Kubo, S. Piperdi, J. Rosenblum et al., "Platelet-derived growth factor receptor as a prognostic marker and a therapeutic target for imatinib mesylate therapy in osteosarcoma," Cancer, vol. 112, no. 10, pp. 2119-2129, 2008.

[38] M. S. Merchant, C. W. Woo, C. L. Mackall, and C. J. Thiele, "Potential use of imatinib in Ewing's sarcoma: evidence for in vitro and in vivo activity," Journal of the National Cancer Institute, vol. 94, no. 22, pp. 1673-1679, 2002.

[39] M. Hotfilder, C. Lanvers, H. Jürgens, J. Boos, and J. Vormoor, "C-KIT-expressing Ewing tumour cells are insensitive to imatinib mesylate (STI571)," Cancer Chemotherapy and Pharmacology, vol. 50, no. 2, pp. 167-169, 2002.

[40] R. Chugh, J. K. Wathen, R. G. Maki et al., "Phase II multicenter trial of imatinib in 10 histologic subtypes of sarcoma using a bayesian hierarchical statistical model," Journal of Clinical Oncology, vol. 27, no. 19, pp. 3148-3153, 2009.

[41] J. Chao, G. T. Budd, P. Chu et al., "Phase II clinical trial of imatinib mesylate in therapy of KIT and/or PDGFR $\alpha$ expressing ewing sarcoma family of tumors and desmoplastic small round cell tumors," AntiCancer Research, vol. 30, no. 2, pp. 547-552, 2010.

[42] M. Bond, M. L. Bernstein, A. Pappo et al., "A phase II study of imatinib mesylate in children with refractory or relapsed solid tumors: a children's oncology group study," Pediatric Blood and Cancer, vol. 50, no. 2, pp. 254-258, 2008.

[43] I. González, E. J. Andreu, A. Panizo et al., "Imatinib inhibits proliferation of Ewing tumor cells mediated by the stem cell factor/KIT receptor pathway, and sensitizes cells to vincristine and doxorubicin-induced apoptosis," Clinical Cancer Research, vol. 10, no. 2, pp. 751-761, 2004.

[44] F. Timeus, N. Crescenzio, A. Fandi, A. Doria, L. Foglia, and L. C. di Montezemolo, "In vitro antiproliferative and antimigratory activity of dasatinib in neuroblastoma and Ewing sarcoma cell lines," Oncology Reports, vol. 19, no. 2, pp. 353$359,2008$.

[45] P. Hingorani, W. Zhang, R. Gorlick, and E. A. Kolb, "Inhibition of Src phosphorylation alters metastatic potential of osteosarcoma in vitro but not in vivo," Clinical Cancer Research, vol. 15, no. 10, pp. 3416-3422, 2009.

[46] R. Aplenc, S. M. Blaney, L. C. Strauss et al., "Pediatric phase I trial and pharmacokinetic study of dasatinib: a report from the children's oncology group phase I consortium," Journal of Clinical Oncology, vol. 29, no. 7, pp. 839-844, 2011.

[47] Y. Pignochino, G. Grignani, G. Cavalloni et al., "Sorafenib blocks tumour growth, angiogenesis and metastatic potential in preclinical models of osteosarcoma through a mechanism potentially involving the inhibition of ERK1/2, MCL-1 and ezrin pathways," Molecular Cancer, vol. 8, article 118, 2009.

[48] G. Grignani, E. Palmerini, and P. Dileo, "A phase II trial of sorafenib in relapsed and unresectable high-grade 10 osteosarcoma after failure of standard multimodal therapy: an Italian Sarcoma Group study," Annals of Oncology, vol. 23, no. 2, pp. 508-516, 2012.

[49] J. M. Maris, J. Courtright, P. J. Houghton et al., "Initial testing (stage 1) of sunitinib by the pediatric preclinical testing program," Pediatric Blood and Cancer, vol. 51, no. 1, pp. 4248,2008 . 
[50] S. G. DuBois, S. Shusterman, J. M. Reid et al., "Tolerability and pharmacokinetic profile of a sunitinib powder formulation in pediatric patients with refractory solid tumors: a Children's Oncology Group study," Cancer Chemother Pharmacol, vol. 69, no. 4, pp. 1021-1027, 2012.

[51] S. G. DuBois, S. Shusterman, A. M. Ingle et al., "Phase I and pharmacokinetic study of sunitinib in pediatric patients with refractory solid tumors: a children's oncology group study," Clinical Cancer Research, vol. 17, no. 15, pp. 5113-5122, 2011.

[52] S. T. Keir, J. M. Maris, R. Lock et al., "Initial testing (stage 1) of the multi-targeted kinase inhibitor sorafenib by the pediatric preclinical testing program," Pediatric Blood and Cancer, vol. 55, no. 6, pp. 1126-1133, 2010.

[53] S. Kumar, R. B. Mokhtari, R. Sheikh et al., "Metronomic oral topotecan with pazopanib is an active antiangiogenic regimen in mouse models of aggressive pediatric solid tumor," Clinical Cancer Research, vol. 17, no. 17, pp. 5656-5667, 2011.

[54] J. L. Glade Bender, A. Lee, P. C. Adamson et al., "Phase I study of pazopanib in children with relapsed or refractory solid tumors (ADVL0815): a Children's Oncology Group Phase I Consortium Trial," Journal of Clinical Oncology, vol. 29, supplement, abstract 9501, 2011.

[55] T. Bachelot, C. Bourgier, C. Cropet et al., "Randomized phase II trial of everolimus in combination with tamoxifen in patients with hormone receptor-positive, human epidermal growth factor receptor 2-negative metastatic breast cancer with prior exposure to aromatase inhibitors: a GINECO study," Journal of Clinical Oncology, vol. 30, no. 22, pp. 2718 2724, 2012.

[56] H. S. Rugo and S. Keck, "Reversing hormone resistance: have we found the golden key?" Journal of Clinical Oncology, vol. 30, no. 22, pp. 2707-2709, 2012.

[57] W. Fu, M. Le, B. Chu et al., "The cyclin-dependent kinase inhibitor SCH 727965 (dinacliclib) induces the apoptosis of osteosarcoma cells," Molecular Cancer Therapeutics, vol. 10, no. 6, pp. 1018-1027, 2011.

[58] S. P. Chawla, V. S. Chua, L. Fernandez et al., "Phase I/II and phase II studies of targeted gene delivery In vivo: intravenous rexin-g for chemotherapy-resistant sarcoma and osteosarcoma," Molecular Therapy, vol. 17, no. 9, pp. 1651-1657, 2009.

[59] J. M. Maris, C. L. Morton, R. Gorlick et al., "Initial testing of the Aurora kinase a inhibitor MLN8237 by the Pediatric Preclinical Testing Program (PPTP)," Pediatric Blood and Cancer, vol. 55, no. 1, pp. 26-34, 2010.

[60] A. G. Morales, M. S. Brassesco, J. A. Pezuk et al., "BI 2536mediated PLK1 inhibition suppresses HOS and MG-63 osteosarcoma cell line growth and clonogenicity," AntiCancer Drugs, vol. 22, pp. 995-1001, 2011.

[61] L. T. Vassilev, B. T. Vu, B. Graves et al., "In Vivo Activation of the p53 Pathway by Small-Molecule Antagonists of MDM2," Science, vol. 303, no. 5659, pp. 844-848, 2004.

[62] C. Tovar, J. Rosinski, Z. Filipovic et al., "Small-molecule MDM2 antagonists reveal aberrant p53 signaling in cancer: implications for therapy," Proceedings of the National Academy of Sciences of the United States of America, vol. 103, no. 6, pp. 1888-1893, 2006.

[63] J. Sonnemann, C. D. Palani, S. Wittig et al., "Anticancer effects of the p53 activator nutlin-3 in Ewing's sarcoma cells," European Journal of Cancer, vol. 47, no. 9, pp. 1432-1441, 2011.

[64] D. Javelaud and F. Besançon, "NF- $\kappa$ B activation results in rapid inactivation of JNK in TNF $\alpha$-treated Ewing sarcoma cells: a mechanism for the anti-apoptotic effect of NF- $\kappa \mathrm{B}$," Oncogene, vol. 20, no. 32, pp. 4365-4372, 2001.
[65] C. D. Palani, J. F. Beck, and J. Sonnemann, "Histone deacetylase inhibitors enhance the anticancer activity of nutlin-3 and induce p53 hyperacetylation and downregulation of MDM2 and MDM4 gene expression," Investigational New Drugs, pp. $1-12,2010$.

[66] S. Bruheim, Y. Xi, J. Ju, and O. Fodstad, "Gene expression profiles classify human osteosarcoma xenografts according to sensitivity to doxorubicin, cisplatin, and ifosfamide," Clinical Cancer Research, vol. 15, no. 23, pp. 7161-7169, 2009.

[67] M. Puglisi, L. van Doorn, M. Blanco-Codesido et al., "A phase I safety and pharmacokinetic (PK) study of navitoclax (N) in combination with docetaxel (D) in patients (pts) with solid tumors," Journal of Clinical Oncology, vol. 29, supplement, abstract 2518, 2011.

[68] G. Picarda, F. Lamoureux, L. Geffroy et al., "Preclinical evidence that use of TRAIL in Ewing's sarcoma and osteosarcoma therapy inhibits tumor growth, prevents osteolysis, and increases animal survival," Clinical Cancer Research, vol. 16, no. 8, pp. 2363-2374, 2010.

[69] Y. Wang, D. Mandal, S. Wang et al., "Platelet-derived growth factor receptor $\beta$ inhibition increases tumor necrosis factorrelated apoptosis-inducing ligand (TRAIL) sensitivity: imatinib and TRAIL dual therapy," Cancer, vol. 116, no. 16, pp. 3892-3902, 2010.

[70] P. J. Kaplan-Lefko, J. D. Graves, S. J. Zoog et al., "Conatumumab, a fully human agonist antibody to death receptor 5 , induces apoptosis via caspase activation in multiple tumor types," Cancer Biology and Therapy, vol. 9, no. 8, pp. 618-631, 2010.

[71] S. P. Chawla, A. C. Lockhart, N. Azad et al., "Efficacy and safety of conatumumab plus AMG 479 in patients with advanced sarcoma," in Proceedings of the CTOS Meeting, Chicago, Ill, USA, 2010.

[72] G. D. Demetri, A. Le Cesne, S. P. Chawla et al., "First-line treatment of metastatic or locally advanced unresectable soft tissue sarcomas with conatumumab in combination with doxorubicin or doxorubicin alone: a phase I/II open-label and double-blind study," European Journal of Cancer, vol. 48, no. 4, pp. 547-563, 2012.

[73] P. J. Houghton, M. H. Kang, C. P. Reynolds et al., "Initial testing (stage 1) of LCL161, a SMAC mimetic, by the pediatric preclinical testing program," Pediatr Blood Cancer, vol. 58, no. 4, pp. 636-639, 2012.

[74] S. V. Holt, K. E. Brookes, C. Dive, and G. W. J. Makin, "Down-regulation of XIAP by AEG35156 in paediatric tumour cells induces apoptosis and sensitises cells to cytotoxic agents," Oncology Reports, vol. 25, no. 4, pp. 1177-1181, 2011.

[75] J. C. Brenner, F. Y. Feng, S. Han et al., "PARP-1 inhibition as a targeted strategy to treat Ewing's sarcoma," Cancer Research, vol. 72, no. 7, pp. 1608-1613, 2012.

[76] Y. F. Wu, X. J. Liang, Y. Y. Liu et al., "+Antisense oligonucleotide targeting survivin inhibits growth by inducing apoptosis in human osteosarcoma cells MG-63," Neoplasma, vol. 57, no. 6, pp. 501-506, 2010.

[77] J. Zou, M. Gan, N. Mao, X. Zhu, Q. Shi, and H. Yang, "Sensitization of osteosarcoma cell line SaOS-2 to chemotherapy by downregulating survivin," Archives of Medical Research, vol. 41, no. 3, pp. 162-169, 2010.

[78] J. Huang, K. Liu, Y. Yu et al., "Targeting HMGB1-mediated autophagy as a novel therapeutic strategy for osteosarcoma," Autophagy, vol. 8, no. 2, pp. 275-277, 2012.

[79] J. Huang, J. Ni, K. Liu et al., "HMGB1 promotes drug resistance in osteosarcoma," Cancer Research, vol. 72, no. 1, pp. 230-238, 2012. 
[80] N. V. Rao, B. Argyle, X. Xu et al., "Low anticoagulant heparin targets multiple sites of inflammation, suppresses heparininduced thrombocytopenia, and inhibits interaction of RAGE with its ligands," American Journal of Physiology, vol. 299, no. 1, pp. C97-C110, 2010.

[81] E. Sotillo-Piñeiro, L. Sierrasesúmaga, and A. Patiño-García, "Telomerase activity and telomere length in primary and metastatic tumors from pediatric bone cancer patients," Pediatric Research, vol. 55, no. 2, pp. 231-235, 2004.

[82] J. Fujimori, T. Matsuo, S. Shimose et al., "Antitumor effects of telomerase inhibitor TMPyP4 in osteosarcoma cell lines," Journal of Orthopaedic Research, vol. 29, pp. 1707-1711, 2011.

[83] A. Takahashi, F. Higashino, M. Aoyagi et al., "EWS/ETS fusions activate telomerase in Ewing's tumors," Cancer Research, vol. 63, no. 23, pp. 8338-8344, 2003.

[84] K. Trieb and H. Blahovec, "Suramin suppresses growth, alkaline-phosphatase and telomerase activity of human osteosarcoma cells in vitro," International Journal of Biochemistry and Cell Biology, vol. 35, no. 7, pp. 1066-1070, 2003.

[85] O. Uziel, E. Fenig, J. Nordenberg et al., "Imatinib mesylate (Gleevec) downregulates telomerase activity and inhibits proliferation in telomerase-expressing cell lines," British Journal of Cancer, vol. 92, no. 10, pp. 1881-1891, 2005.

[86] C. Lanvers-Kaminsky, B. Winter, S. Koling et al., "Doxorubicin modulates telomerase activity in Ewing's sarcoma in vitro and in vivo," Oncology Reports, vol. 14, no. 3, pp. 751758, 2005.

[87] A. Schuck, C. Poremba, C. Lanvers et al., "Radiation-induced changes of telomerase activity in a human Ewing xenograft tumor," Strahlentherapie und Onkologie, vol. 178, no. 12, pp. 701-708, 2002.

[88] K. S. Stewart and E. S. Kleinerman, "Tumor vessel development and expansion in Ewing's sarcoma: a review of the vasculogenesis process and clinical trials with vasculartargeting agents," Sarcoma, vol. 2011, Article ID 165837, 7 pages, 2011.

[89] H. Mizobuchi, J. M. García-Castellano, S. Philip, J. H. Healey, and R. Gorlick, "Hypoxia markers in human osteosarcoma: an exploratory study," Clinical Orthopaedics and Related Research, vol. 466, no. 9, pp. 2052-2059, 2008.

[90] J. Bajpai, M. Sharma, V. Sreenivas et al., "VEGF expression as a prognostic marker in osteosarcoma," Pediatric Blood and Cancer, vol. 53, no. 6, pp. 1035-1039, 2009.

[91] Q. C. Yang, B. F. Zeng, Z. M. Shi et al., "Inhibition of hypoxiainduced angiogenesis by trichostatin A via suppression of HIF-1a activity in human osteosarcoma," Journal of Experimental and Clinical Cancer Research, vol. 25, no. 4, pp. 593599, 2006.

[92] D. N. T. Aryee, S. Niedan, M. Kauer et al., "Hypoxia modulates EWS-FLI1 transcriptional signature and enhances the malignant properties of Ewing's Sarcoma cells In vitro," Cancer Research, vol. 70, no. 10, pp. 4015-4023, 2010.

[93] Q. C. Yang, B. F. Zeng, Y. Dong, Z. M. Shi, Z. M. Jiang, and J. Huang, "Overexpression of hypoxia-inducible factor- $1 \alpha$ in human osteosarcoma: correlation with clinicopathological parameters and survival outcome," Japanese Journal of Clinical Oncology, vol. 37, no. 2, pp. 127-134, 2007.

[94] H. J. Knowles, K. L. Schaefer, U. Dirksen, and N. A. Athanasou, "Hypoxia and hypoglycaemia in Ewing's sarcoma and osteosarcoma: regulation and phenotypic effects of Hypoxia-Inducible Factor," BMC Cancer, vol. 10, article 372, 2010.

[95] J. M. Maris, J. Courtright, P. J. Houghton et al., "Initial testing of the VEGFR inhibitor AZD2171 by the Pediatric Preclinical
Testing Program," Pediatric Blood and Cancer, vol. 50, no. 3, pp. 581-587, 2008.

[96] C. L. Morton, J. M. Maris, S. T. Keir et al., "Combination testing of cediranib (AZD2171) against childhood cancer models by the pediatric preclinical testing program," Pediatric Blood \& Cancer, vol. 58, no. 4, pp. 566-571, 2012.

[97] E. Pencreach, E. Guérin, C. Nicolet et al., "Marked activity of irinotecan and rapamycin combination toward colon cancer cells in vivo and in vitro is mediated through cooperative modulation of the mammalian target of rapamycin/hypoxialnducible factor- $1 \alpha$ axis," Clinical Cancer Research, vol. 15, no. 4, pp. 1297-1307, 2009.

[98] J. PosthumaDeBoer, M. A. Witlox, G. J. Kaspers, and B. J. van Royen, "Molecular alterations as target for therapy in metastatic osteosarcoma: a review of literature," Clinical and Experimental Metastasis, vol. 28, no. 5, pp. 493-503, 2011.

[99] D. P. M. Hughes, "How the NOTCH pathway contributes to the ability of osteosarcoma cells to metastasize," Cancer Treatment and Research, vol. 152, pp. 479-496, 2009.

[100] F. Baliko, T. Bright, R. Poon, B. Cohen, S. E. Egan, and B. A. Alman, "Inhibition of notch signaling induces neural differentiation in Ewing sarcoma," American Journal of Pathology, vol. 170, no. 5, pp. 1686-1694, 2007.

[101] D. J. Deangelo, R. M. Stone, L. B. Silverman et al., "A phase I clinical trial of the notch inhibitor MK-0752 in patients with T-cell acute lymphoblastic leukemia/lymphoma (T-ALL) and other leukemias," Journal of Clinical Oncology, vol. 24, 8S, abstract 6585, ASCO Annual Meeting Proceedings Part I, 2006.

[102] M. Fouladi, C. F. Stewart, J. Olson et al., "Phase I trial of MK-0752 in children with refractory CNS malignancies: a pediatric brain tumor consortium study," Journal of Clinical Oncology, vol. 29, no. 26, pp. 3529-3534, 2011.

[103] N. Coltella, M. C. Manara, V. Cerisano et al., "Role of the MET/HGF receptor in proliferation and invasive behavior of osteosarcoma," The FASEB Journal, vol. 17, no. 9, pp. 11621164, 2003.

[104] N. Entz-Werle, T. Lavaux, N. Metzger et al., "Involvement of MET/TWIST/APC combination or the potential role of ossification factors in pediatric high-grade osteosarcoma oncogenesis," Neoplasia, vol. 9, no. 8, pp. 678-688, 2007.

[105] A. T. Liao, J. McCleese, S. Kamerling, J. Christensen, and C. A. London, "A novel small molecule Met inhibitor, PF2362376, exhibits biological activity against osteosarcoma," Veterinary and Comparative Oncology, vol. 5, no. 3, pp. 177-196, 2007.

[106] E. R. Sampson, B. A. Martin, A. E. Morris et al., "The orally bioavailable met inhibitor PF-2341066 inhibits osteosarcoma growth and osteolysis/matrix production in a xenograft model," Journal of Bone and Mineral Research, vol. 26, no. 6, pp. 1283-1294, 2011.

[107] Y. Cai, A. B. Mohseny, M. Karperien, P. C. W. Hogendoorn, G. Zhou, and A. M. Cleton-Jansen, "Inactive Wnt/ $\beta$-catenin pathway in conventional high-grade osteosarcoma," Journal of Pathology, vol. 220, no. 1, pp. 24-33, 2010.

[108] L. H. Brail, J. E. Gray, H. Burris et al., "A phase I doseescalation, pharmacokinetic (PK), and pharmacodynamic (PD) evaluation of intravenous LY2090314 a GSK3 inhibitor administered in combination with pemetrexed and carboplatin," Journal of Clinical Oncology, vol. 29, 15s, supplement, abstract 3030, 2011.

[109] L. L. Worth, E. A. Lafleur, S. F. Jia, and E. S. Kleinerman, "Fas expression inversely correlates with metastatic potential in osteosarcoma cells," Oncology Reports, vol. 9, no. 4, pp. 823827, 2002. 
[110] K. Krishnan, C. Khanna, and L. J. Helman, "The biology of metastases in pediatric sarcomas," Cancer Journal, vol. 11, no. 4, pp. 306-313, 2005.

[111] X. Wan, S. Y. Kim, L. M. Guenther et al., "Beta4 integrin promotes osteosarcoma metastasis and interacts with ezrin," Oncogene, vol. 28, no. 38, pp. 3401-3411, 2009.

[112] I. Tsagaraki, E. C. Tsilibary, and A. K. Tzinia, "TIMP-1 interaction with $\alpha \mathrm{v} \beta 3$ integrin confers resistance to human osteosarcoma cell line MG-63 against TNF- $\alpha$-induced apoptosis," Cell and Tissue Research, vol. 342, no. 1, pp. 87-96, 2010.

[113] T. J. MacDonald, C. F. Stewart, M. Kocak et al., "Phase I clinical trial of cilengitide in children with refractory brain tumors: pediatric brain tumor consortium study PBTC-012," Journal of Clinical Oncology, vol. 26, no. 6, pp. 919-924, 2008.

[114] G. De Angulo, M. Hernandez, J. Morales-Arias et al., "Early lymphocyte recovery as a prognostic indicator for high-risk Ewing sarcoma," Journal of Pediatric Hematology/Oncology, vol. 29, no. 1, pp. 48-52, 2007.

[115] C. Moore, D. Eslin, A. Levy, J. Roberson, V. Giusti, and R. Sutphin, "Prognostic significance of early lymphocyte recovery in pediatric osteosarcoma," Pediatric Blood and Cancer, vol. 55, no. 6, pp. 1096-1102, 2010.

[116] J. Sancéau, M. F. Poupon, O. Delattre, X. Sastre-Garau, and J. Wietzerbin, "Strong inhibition of Ewing tumor xenograft growth by combination of human interferon-alpha or interferon-beta with ifosfamide," Oncogene, vol. 21, no. 50, pp. 7700-7709, 2002.

[117] J. Sancéau and J. Wietzerbin, "Downregulation of angiogenic factors in Ewing tumor xenografts by the combination of human interferon- $\alpha$ or interferon- $\beta$ with ifosfamide," Annals of the New York Academy of Sciences, vol. 1030, pp. 170-178, 2004.

[118] D. Berghuis, S. J. Santos, H. J. Baelde et al., "Pro-inflammatory chemokine-chemokine receptor interactions within the Ewing sarcoma microenvironment determine CD8+ T-lymphocyte infiltration and affect tumour progression," Journal of Pathology, vol. 223, no. 3, pp. 347-357, 2011.

[119] T. Fujiwara, J. Fukushi, S. Yamamoto et al., "Macrophage infiltration predicts a poor prognosis for human ewing sarcoma," American Journal of Pathology, vol. 179, no. 3, pp. 1157-1170, 2011.

[120] N. Gaspar, A. Rey, P. M. Bérard et al., "Risk adapted chemotherapy for localised Ewing's sarcoma of bone: the French EW93 study," European Journal of Cancer, vol. 48, no. 9, pp. 1376-1385, 2012.

[121] B. Liu, Z. L. Shi, J. Feng, and H. M. Tao, "Celecoxib, a cyclooxygenase-2 inhibitor, induces apoptosis in human osteosarcoma cell line MG-63 via down-regulation of PI3K/Akt," Cell Biology International, vol. 32, no. 5, pp. 494501, 2008.

[122] A. S. Gendy, A. Lipskar, R. D. Glick, B. M. Steinberg, M. Edelman, and S. Z. Soffer, "Selective inhibition of cyclooxygenase-2 suppresses metastatic disease without affecting primary tumor growth in a murine model of Ewing sarcoma," Journal of Pediatric Surgery, vol. 46, no. 1, pp. 108114, 2011.

[123] M. Lipinski, K. Braham, and I. Philip, "Neuroectodermassociated antigens on Ewing's sarcoma cell lines," Cancer Research, vol. 47, no. 1, pp. 183-187, 1987.

[124] J. P. Heiner, F. Miraldi, S. Kallick et al., "Localization of G(D2)-specific monoclonal antibody 3F8 in human osteosarcoma," Cancer Research, vol. 47, no. 20, pp. 5377-5381, 1987.
[125] A. L. Yu, A. L. Gilman, M. F. Ozkaynak et al., "Anti-GD2 antibody with GM-CSF, interleukin-2, and isotretinoin for neuroblastoma," New England Journal of Medicine, vol. 363, no. 14, pp. 1324-1334, 2010.

[126] A. L. Yu, M. M. Uttenreuther-Fischer, C. S. Huang et al., "Phase I trial of a human-mouse chimeric anti-disialoganglioside monoclonal antibody ch14.18 in patients with refractory neuroblastoma and osteosarcoma," Journal of Clinical Oncology, vol. 16, no. 6, pp. 2169-2180, 1998.

[127] S. Kailayangiri, B. Altvater, J. Meltzer et al., "The ganglioside antigen G(D2) is surface-expressed in Ewing sarcoma and allows for MHC-independent immune targeting," British Journal of Cancer, vol. 106, no. 6, pp. 1123-1133, 2012.

[128] E. K. Waller, "The role of sargramostim (rhGM-CSF) as immunotherapy," Oncologist, vol. 12, no. 2, pp. 22-26, 2007.

[129] C. A. S. Arndt, N. V. Koshkina, C. Y. Inwards et al., "Inhaled granulocyte-macrophage colony stimulating factor for first pulmonary recurrence of osteosarcoma: effects on diseasefree survival and immunomodulation. A report from the Children's Oncology Group," Clinical Cancer Research, vol. 16, no. 15, pp. 4024-4030, 2010.

[130] F. Meyer-Wentrup, G. Richter, and S. Burdach, "Identification of an immunogenic EWS-FLI1-derived HLA-DRrestricted T helper cell epitope," Pediatric Hematology and Oncology, vol. 22, no. 4, pp. 297-308, 2005.

[131] T. Kubo, S. Shimose, T. Matsuo, J. Fujimori, K. Arihiro, and M. Ochi, "Interferon- $\alpha / \beta$ receptor as a prognostic marker in osteosarcoma," Journal of Bone and Joint Surgery Series A, vol. 93, no. 6, pp. 519-526, 2011.

[132] E. P. Buddingh, M. L. Kuijjer, R. A. J. Duim et al., "Tumorinfiltrating macrophages are associated with metastasis suppression in high-grade osteosarcoma: a rationale for treatment with macrophage activating agents," Clinical Cancer Research, vol. 17, no. 8, pp. 2110-2119, 2011.

[133] J. Whelan, D. Patterson, M. Perisoglou et al., "The role of interferons in the treatment of osteosarcoma," Pediatric Blood and Cancer, vol. 54, no. 3, pp. 350-354, 2010.

[134] Z. Li, Q. Xu, H. Peng, R. Cheng, Z. Sun, and Z. Ye, "IFN$\gamma$ enhances HOS and U2OS cell lines susceptibility to $\gamma \delta \mathrm{T}$ cell-mediated killing through the Fas/Fas ligand pathway," International Immunopharmacology, vol. 11, no. 4, pp. 496503, 2011.

[135] L. Kager, U. Potschger, S. Bielack et al., "Review of mifamurtide in the treatment of patients with osteosarcoma," Therapeutics and Clinical Risk Management, vol. 6, pp. 279286, 2010.

[136] Y. Wittrant, S. Théoleyre, C. Chipoy et al., "RANKL/RANK/ OPG: new therapeutic targets in bone tumours and associated osteolysis," Biochimica et Biophysica Acta, vol. 1704, no. 2, pp. 49-57, 2004.

[137] D. H. Jones, T. Nakashima, O. H. Sanchez et al., "Regulation of cancer cell migration and bone metastasis by RANKL," Nature, vol. 440, no. 7084, pp. 692-696, 2006.

[138] S. Avnet, A. Longhi, M. Salerno et al., "Increased osteoclast activity is associated with aggressiveness of osteosarcoma," International Journal of Oncology, vol. 33, no. 6, pp. 12311238,2008

[139] J. A. Lee, J. S. Jung, D. H. Kim et al., "RANKL expression is related to treatment outcome of patients with localized, highgrade osteosarcoma," Pediatric Blood and Cancer, vol. 56, no. 5, pp. 738-743, 2011.

[140] Z. Zhou, H. Guan, X. Duan, and E. S. Kleinerman, "Zoledronic acid inhibits primary bone tumor growth in Ewing sarcoma," Cancer, vol. 104, no. 8, pp. 1713-1720, 2005. 
[141] R. Tenta, N. Pitulis, D. Tiblalexi et al., "Mechanisms of the action of zoledronic acid on human MG-63 osteosarcoma cells," Hormone and Metabolic Research, vol. 40, no. 11, pp. 737-745, 2008.

[142] T. Iguchi, Y. Miyakawa, K. Saito et al., "Zoledronate-induced $S$ phase arrest and apoptosis accompanied by DNA damage and activation of the ATM/Chk1/cdc25 pathway in human osteosarcoma cells," International Journal of Oncology, vol. 31, no. 2, pp. 285-291, 2007.

[143] B. Ory, F. Blanchard, S. Battaglia, F. Gouin, F. Rédini, and D. Heymann, "Zoledronic acid activates the DNA S-phase checkpoint and induces osteosarcoma cell death characterized by apoptosis-inducing factor and endonuclease$\mathrm{G}$ translocation independently of p53 and retinoblastoma status," Molecular Pharmacology, vol. 71, no. 1, pp. 333-343, 2007.

[144] A. Evdokiou, A. Labrinidis, S. Bouralexis, S. Hay, and D. M. Findlay, "Induction of cell death of human osteogenic sarcoma cells by zoledronic acid resembles anoikis," Bone, vol. 33, no. 2, pp. 216-228, 2003.

[145] D. Fu, X. He, S. Yang, W. Xu, T. Lin, and X. Feng, “Zoledronic acid inhibits vasculogenic mimicry in murine osteosarcoma cell line in vitro," BMC Musculoskeletal Disorders, vol. 12, article 146, 2011.

[146] D. Heymann, B. Ory, F. Blanchard et al., "Enhanced tumor regression and tissue repair when zoledronic acid is combined with ifosfamide in rat osteosarcoma," Bone, vol. 37, no. 1, pp. 74-86, 2005.

[147] A. Labrinidis, S. Hay, V. Liapis, D. M. Findlay, and A. Evdokiou, "Zoledronic acid protects against osteosarcomainduced bone destruction but lacks efficacy against pulmonary metastases in a syngeneic rat model," International Journal of Cancer, vol. 127, no. 2, pp. 345-354, 2010.

[148] C. R. Dass and P. F. M. Choong, "Zoledronic acid inhibits osteosarcoma growth in an orthotopic model," Molecular Cancer Therapeutics, vol. 6, no. 12, pp. 3263-3270, 2007.

[149] K. Koto, N. Horie, S. Kimura et al., "Clinically relevant dose of zoledronic acid inhibits spontaneous lung metastasis in a murine osteosarcoma model," Cancer Letters, vol. 274, no. 2, pp. 271-278, 2009.

[150] L. Endo-Munoz, A. Cumming, D. Rickwood et al., "Loss of osteoclasts contributes to development of osteosarcoma pulmonary metastases," Cancer Research, vol. 70, no. 18, pp. 7063-7072, 2010.

[151] M. S. Benassi, A. Chiechi, F. Ponticelli et al., "Growth inhibition and sensitization to cisplatin by zoledronic acid in osteosarcoma cells," Cancer Letters, vol. 250, no. 2, pp. 194 205, 2007.

[152] K. Ryu, H. Murata, K. Koto et al., "Combined effects of bisphosphonate and radiation on osteosarcoma cells," AntiCancer Research, vol. 30, no. 7, pp. 2713-2720, 2010.

[153] G. A. Odri, S. Dumoucel, G. Picarda et al., "Zoledronic acid as a new adjuvant therapeutic strategy for Ewing's sarcoma patients," Cancer Research, vol. 70, no. 19, pp. 7610-7619, 2010.

[154] S. Battaglia, S. Dumoucel, J. Chesneau et al., "Impact of oncopediatric dosing regimen of zoledronic acid on bone growth: preclinical studies and case report of an osteosarcoma pediatric patient," Journal of Bone and Mineral Research, vol. 26, no. 10, pp. 2439-2451, 2011.

[155] T. Akiyama, C. R. Dass, Y. Shinoda, H. Kawano, S. Tanaka, and P. F. M. Choong, "Systemic RANK-Fc protein therapy is efficacious against primary osteosarcoma growth in a murine model via activity against osteoclasts," Journal of Pharmacy and Pharmacology, vol. 62, no. 4, pp. 470-476, 2010.

[156] F. Lamoureux, G. Picarda, J. Rousseau et al., "Therapeutic efficacy of soluble receptor activator of nuclear factor- $\kappa \mathrm{B}-$ Fc delivered by nonviral gene transfer in a mouse model of osteolytic osteosarcoma," Molecular Cancer Therapeutics, vol. 7, no. 10, pp. 3389-3398, 2008.

[157] F. Lamoureux, P. Richard, Y. Wittrant et al., "Therapeutic relevance of osteoprotegerin gene therapy in osteosarcoma: blockade of the vicious cycle between tumor cell proliferation and bone resorption," Cancer Research, vol. 67, no. 15, pp. 7308-7318, 2007.

[158] J. Rousseau, V. Escriou, F. Lamoureux et al., "Formulated siRNAs targeting Rankl prevent osteolysis and enhance chemotherapeutic response in osteosarcoma models," Journal of Bone and Mineral Research, vol. 26, no. 10, pp. 24522462, 2011.

[159] H. Guan, Z. Zhou, Y. Cao, X. Duan, and E. S. Kleinerman, "VEGF165 promotes the osteolytic bone destruction of ewing's sarcoma tumors by upregulating RANKL," Oncology Research, vol. 18, no. 2-3, pp. 117-125, 2009.

[160] R. Taylor, H. J. Knowles, and N. A. Athanasou, "Ewing sarcoma cells express RANKL and support osteoclastogenesis," Journal of Pathology, vol. 225, no. 2, pp. 195-202, 2011.

[161] K. Fizazi, A. Lipton, X. Mariette et al., "Randomized phase II trial of denosumab in patients with bone metastases from prostate cancer, breast cancer, or other neoplasms after intravenous bisphosphonates," Journal of Clinical Oncology, vol. 27, no. 10, pp. 1564-1571, 2009.

[162] D. Thomas, S. P. Chawla, K. Skubitz et al., "Denosumab treatment of giant cell tumor of bone: interim analysis of an open-label phase II study," Journal of Clinical Oncology, vol. 26, supplement, abstract 10500, 2008.

[163] G. Henriksen, K. Breistøl, Ø. S. Bruland, Ø. Fodstad, and R. H. Larsen, "Significant antitumor effect from bone-seeking, $\alpha$-particle-emitting 223Ra demonstrated in an experimental skeletal metastases model," Cancer Research, vol. 62, no. 11, pp. 3120-3125, 2002.

[164] P. Anderson and R. Nuñez, "Samarium lexidronam (153SmEDTMP): skeletal radiation for osteoblastic bone metastases and osteosarcoma," Expert Review of Anticancer Therapy, vol. 7, no. 11, pp. 1517-1527, 2007.

[165] D. M. Loeb, R. F. Hobbs, A. Okoli et al., "Tandem dosing of samarium-153 ethylenediamine tetramethylene phosphoric acid with stem cell support for patients with high-risk osteosarcoma," Cancer, vol. 116, no. 23, pp. 5470-5478, 2010.

[166] C. Parker, S. Nilsson, D. Heinrich et al., "Updated analysis of the phase III, double-blind, randomized, multinational study of radium-223 chloride in castration-resistant prostate cancer (CRPC) patients with bone metastases (ALSYMPCA)," Journal of Clinical Oncology, vol. 30, supplement, abstract LBA4512, 2012.

[167] M. Hirotsu, T. Setoguchi, H. Sasaki et al., "Smoothened as a new therapeutic target for human osteosarcoma," Molecular Cancer, vol. 9, article 5, 2010.

[168] E. M. Beauchamp, L. Ringer, G. Bulut et al., "Arsenic trioxide inhibits human cancer cell growth and tumor development in mice by blocking Hedgehog/GLI pathway," Journal of Clinical Investigation, vol. 121, no. 1, pp. 148-160, 2011.

[169] J. Warzecha, S. Göttig, K. U. Chow et al., "Inhibition of osteosarcoma cell proliferation by the hedgehog-inhibitor cyclopamine," Journal of Chemotherapy, vol. 19, no. 5, pp. 554-561, 2007. 
[170] H. Zhao, W. Guo, C. Peng, T. Ji, and X. Lu, "Arsenic trioxide inhibits the growth of Adriamycin resistant osteosarcoma cells through inducing apoptosis," Molecular Biology Reports, vol. 37, no. 5, pp. 2509-2515, 2010.

[171] J. Kim, J. Y. Tang, R. Gong et al., "Itraconazole, a commonly used antifungal that inhibits hedgehog pathway activity and cancer growth," Cancer Cell, vol. 17, no. 4, pp. 388-399, 2010.

[172] M. Fouladi, J. R. Park, C. F. Stewart et al., "Pediatric phase I trial and pharmacokinetic study of vorinostat: a children's oncology group phase I consortium report," Journal of Clinical Oncology, vol. 28, no. 22, pp. 3623-3629, 2010.

[173] J. M. Su, X. N. Li, P. Thompson et al., "Phase 1 study of valproic acid in pediatric patients with refractory solid or CNS tumors: a children's oncology group report," Clinical Cancer Research, vol. 17, no. 3, pp. 589-597, 2011.

[174] T. Hirose, Y. Sowa, S. Takahashi et al., "p53-independent induction of Gadd45 by histone deacetylase inhibitor: coordinate regulation by transcription factors Oct-1 and NF-Y," Oncogene, vol. 22, no. 49, pp. 7762-7773, 2003.

[175] C. Blattmann, S. Oertel, V. Ehemann et al., "Enhancement of radiation response in osteosarcoma and rhabdomyosarcoma cell lines by histone deacetylase inhibition," International Journal of Radiation Oncology, Biology, Physics, vol. 78, no. 1, pp. 237-245, 2010.

[176] L. A. Wittenburg, L. Bisson, B. J. Rose, C. Korch, and D. H. Thamm, "The histone deacetylase inhibitor valproic acid sensitizes human and canine osteosarcoma to doxorubicin," Cancer Chemotherapy and Pharmacology, vol. 67, no. 1, pp. 83-92, 2011.

[177] C. Yang, E. Choy, F. J. Hornicek et al., "Histone deacetylase inhibitor (HDACI) PCI-24781 potentiates cytotoxic effects of doxorubicin in bone sarcoma cells," Cancer Chemotherapy and Pharmacology, vol. 67, no. 2, pp. 439-446, 2011.

[178] N. V. Koshkina, K. Rao-Bindal, and E. S. Kleinerman, "Effect of the histone deacetylase inhibitor SNDX-275 on Fas signaling in osteosarcoma cells and the feasibility of its topical application for the treatment of osteosarcoma lung metastases," Cancer, vol. 117, no. 15, pp. 3457-3467, 2011.

[179] K. Watanabe, K. Okamoto, and S. Yonehara, "Sensitization of osteosarcoma cells to death receptor-mediated apoptosis by HDAC inhibitors through downregulation of cellular FLIP," Cell Death and Differentiation, vol. 12, no. 1, pp. 10-18, 2005.

[180] K. Yamanegi, J. Yamane, K. Kobayashi et al., "Sodium valproate, a histone deacetylase inhibitor, augments the expression of cell-surface NKG2D ligands, MICA/B, without increasing their soluble forms to enhance susceptibility of human osteosarcoma cells to NK cell-mediated cytotoxicity," Oncology Reports, vol. 24, no. 6, pp. 1621-1627, 2010.

[181] R. Sakimura, K. Tanaka, F. Nakatani et al., "Antitumor effects of histone deacetylase inhibitor on Ewing's family tumors," International Journal of Cancer, vol. 116, no. 5, pp. 784-792, 2005.

[182] F. Nakatani, K. Tanaka, R. Sakimura et al., "Identification of p21WAF1/CIP1 as a direct target of EWS-Fli1 oncogenic fusion protein," Journal of Biological Chemistry, vol. 278, no. 17, pp. 15105-15115, 2003.

[183] J. Sonnemann, L. Dreyer, M. Hartwig et al., "Histone deacetylase inhibitors induce cell death and enhance the apoptosisinducing activity of TRAIL in Ewing's sarcoma cells," Journal of Cancer Research and Clinical Oncology, vol. 133, no. 11, pp. 847-858, 2007.

[184] T. Okada, K. Tanaka, F. Nakatani et al., "Involvement of Pglycoprotein and MMP1 in resistance to cyclic tetrapeptide subfamily of histone deacetylase inhibitors in the drugresistant osteosarcoma and Ewing's sarcoma cells," International Journal of Cancer, vol. 118, no. 1, pp. 90-97, 2006.

[185] H. Matsubara, M. Watanabe, T. Imai et al., "Involvement of extracellular signal-regulated kinase activation in human osteosarcoma cell resistance to the histone deacetylase inhibitor FK228 [(1S, 4S, 7Z, 10S, 16E, 21R)-7ethylidene-4, 21-bis(propan-2-yl)-2-oxa-12, 13-dithia-5, 8, 20, 23- tetraazabicyclo[8.7.6] tricos-16-ene-3,6,9,19,22-pentone]," Journal of Pharmacology and Experimental Therapeutics, vol. 328, no. 3, pp. 839-848, 2009.

[186] A. S. Martins, J. L. Ordoñez, A. García-Sánchez et al., "A pivotal role for heat shock protein 90 in Ewing sarcoma resistance to anti-insulin-like growth factor 1 receptor treatment: in vitro and in vivo study," Cancer Research, vol. 68, no. 15, pp. 6260-6270, 2008.

[187] R. Bagatell, J. Beliakoff, C. L. David, M. T. Marron, and L. Whitesell, "Hsp90 inhibitors deplete key anti-apoptotic proteins in pediatric solid tumor cells and demonstrate synergistic anticancer activity with cisplatin," International Journal of Cancer, vol. 113, no. 2, pp. 179-188, 2005.

[188] N. Gaspar, S. Y. Sharp, S. Pacey et al., "Acquired resistance to 17-Allylamino-17-Demethoxygeldanamycin (17-A AG, Tanespimycin) in glioblastoma cells," Cancer Research, vol. 69, no. 5, pp. 1966-1975, 2009. 


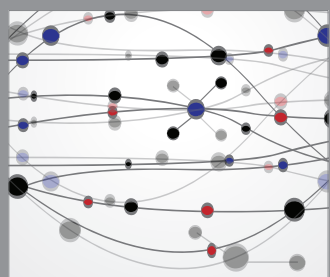

The Scientific World Journal
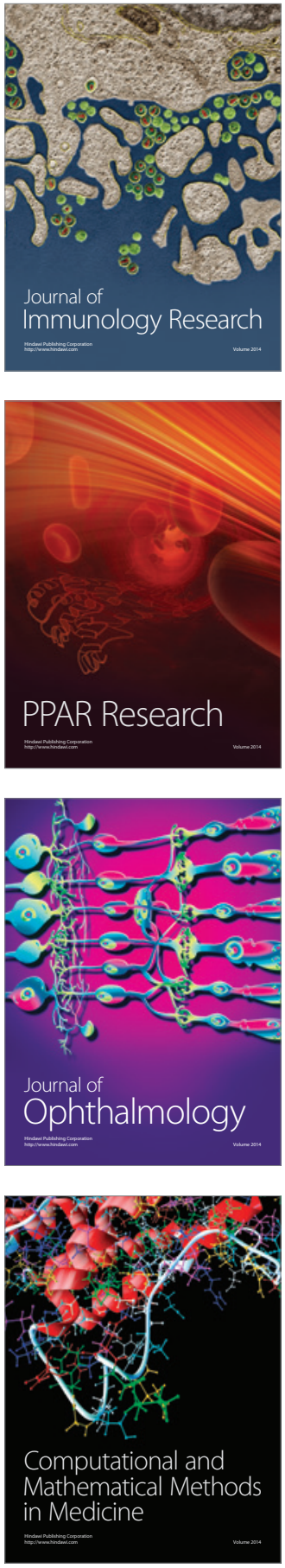

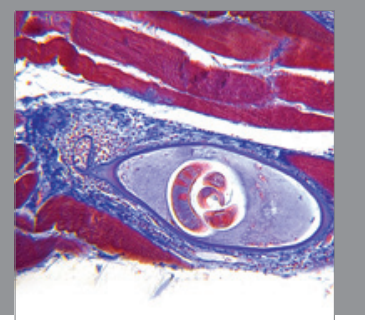

Gastroenterology

Research and Practice
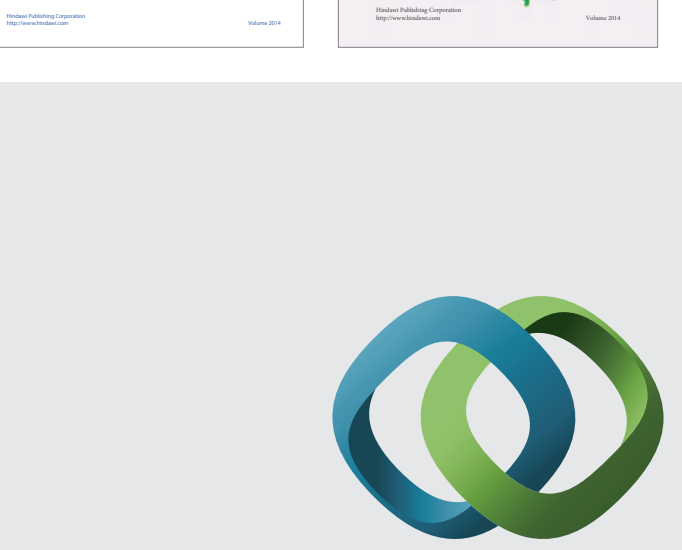

\section{Hindawi}

Submit your manuscripts at

http://www.hindawi.com
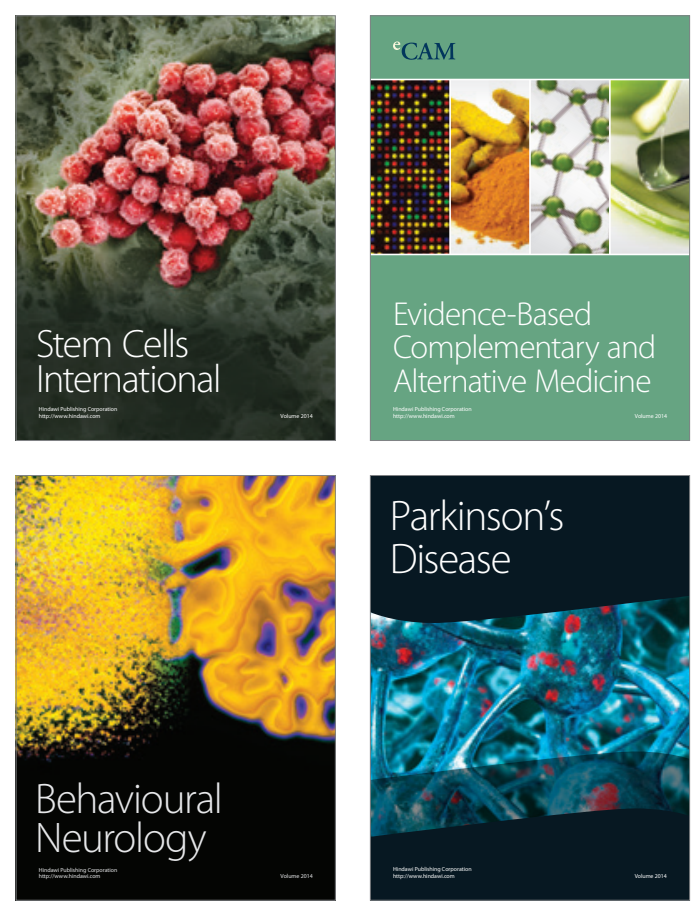

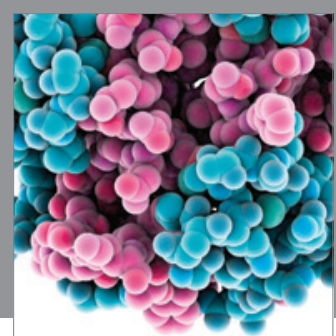

Journal of
Diabetes Research

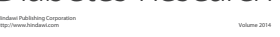

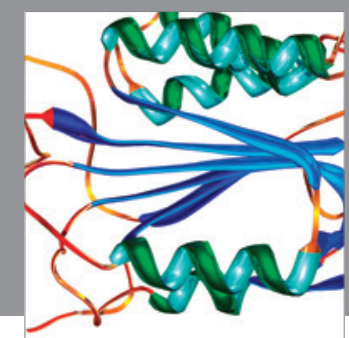

Disease Markers
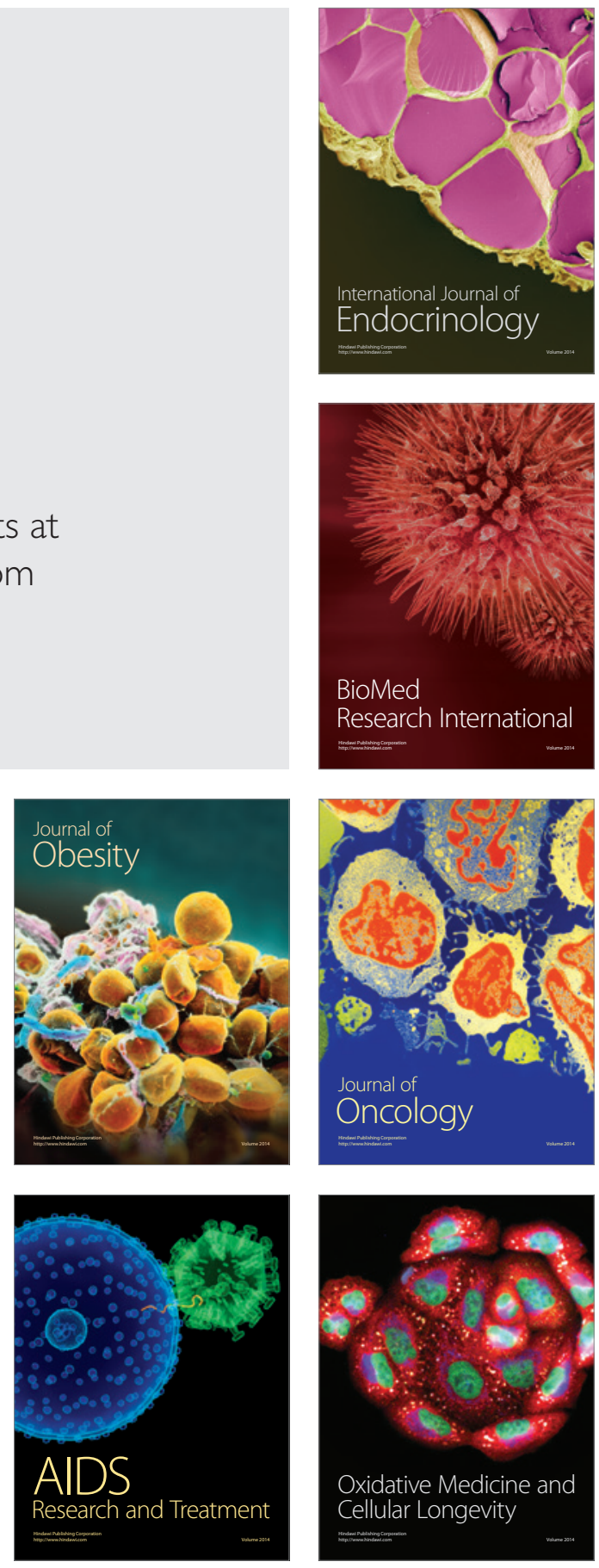